\title{
Radiative forcing estimates of sulfate aerosol in coupled climate-chemistry models with emphasis on the role of the temporal variability
}

\author{
C. Déandreis ${ }^{1}$, Y. Balkanski ${ }^{1}$, J. L. Dufresne ${ }^{2}$, and A. Cozic ${ }^{1}$ \\ ${ }^{1}$ Laboratoire des Sciences du Climat et de l'Environnement, UMR8212, IPSL, CEA-CNRS-UVSQ, \\ Gif-sur-Yvette Cedex, France \\ ${ }^{2}$ Laboratoire de Météorologie Dynamique, LMD/IPSL, CNRS-UPMC, Paris, France
}

Correspondence to: C. Déandreis (cdeipsl@ipsl.jussieu.fr)

Received: 10 May 2011 - Published in Atmos. Chem. Phys. Discuss.: 30 August 2011

Revised: 23 March 2012 - Accepted: 26 March 2012 - Published: 26 June 2012

\begin{abstract}
This paper describes the impact on the sulfate aerosol radiative effects of coupling the radiative code of a global circulation model with a chemistry-aerosol module. With this coupling, temporal variations of sulfate aerosol concentrations influence the estimate of aerosol radiative impacts. Effects of this coupling have been assessed on net fluxes, radiative forcing and temperature for the direct and first indirect effects of sulfate.

The direct effect respond almost linearly to rapid changes in concentrations whereas the first indirect effect shows a strong non-linearity. In particular, sulfate temporal variability causes a modification of the short wave net fluxes at the top of the atmosphere of +0.24 and $+0.22 \mathrm{~W} \mathrm{~m}^{-2}$ for the present and preindustrial periods, respectively. This change is small compared to the value of the net flux at the top of the atmosphere (about $240 \mathrm{~W} \mathrm{~m}^{-2}$ ). The effect is more important in regions with low-level clouds and intermediate sulfate aerosol concentrations (from 0.1 to $0.8 \mu \mathrm{g}\left(\mathrm{SO}_{4}\right) \mathrm{m}^{-3}$ in our model).

The computation of the aerosol direct radiative forcing is quite straightforward and the temporal variability has little effect on its mean value. In contrast, quantifying the first indirect radiative forcing requires tackling technical issues first. We show that the preindustrial sulfate concentrations have to be calculated with the same meteorological trajectory used for computing the present ones. If this condition is not satisfied, it introduces an error on the estimation of the first indirect radiative forcing. Solutions are proposed to assess radiative forcing properly. In the reference method, the
\end{abstract}

coupling between chemistry and climate results in a global average increase of $8 \%$ in the first indirect radiative forcing. This change reaches $50 \%$ in the most sensitive regions. However, the reference method is not suited to run long climate simulations. We present other methods that are simpler to implement in a coupled chemistry/climate model and that offer the possibility to assess radiative forcing.

\section{Introduction}

Aerosols affect the Earth's climate system in two ways: directly and indirectly. Aerosols scatter sunlight and enhance the planetary shortwave (SW) albedo, through the so-called "aerosol direct effect". Indirect effects relate to the modification of cloud radiative properties due to the change of aerosol concentration or properties by human activities. The increase of aerosol number enhances the cloud droplet number concentration. Assuming a cloud liquid water content constant, it is responsible for the decrease of the droplet effective radius and the increase of the cloud reflectivity. Twomey (1974) was amongst the first to describe the so-called first indirect effect. It causes a negative radiative forcing on top of the atmosphere. Despite numerous studies, the uncertainty of the radiative forcing associated with this effect remains much larger than for greenhouse gases. The fourth IPCC report associated to the first indirect effect a negative forcing ranging from -0.2 to $-1.9 \mathrm{~W} \mathrm{~m}^{-2}$ (Forster et al., 2007) and stressed the importance of improving these estimates and 
their associated uncertainties. Chen and Penner (2005) have analysed the uncertainty in the estimation of the first indirect aerosol effect due to emissions, chemical transport model, aerosol size distribution, cloud nucleation parameterization, and different clouds properties. The aerosol burden calculation, the cloud fraction, and the representation of the preindustrial aerosol state (size distribution and mass concentration) are the main sources of uncertainty. Chen and Penner (2005) warn about the use of off-line simulations that could cause additional sources of uncertainty since they use a monthly average aerosol number concentration and argue for a fully coupled GCM, which would give a better estimate of the interactions between aerosols, clouds and radiation.

Part of the difficulty of assessing the aerosol effects on climate comes from their high variability. Aerosols have heterogeneous emission sources and a relatively short lifetime (from day to several weeks) that explains their strong variations in space and time.

Because of this high spatial variability, aerosol effects on climate should not only be assessed at the global scale but also region by region. High temporal variability of aerosol is induced by their large difference in size and the many processes that affect their properties (nucleation, coagulation, sedimentation, wet deposition, humidity growth...). Variations in meteorological fields induce to a large degree the temporal variability in aerosol properties, and there is strong interest to consider the full interactions between them by using coupled climate-chemistry models.

This coupling is expected to introduce non-linearities. Although the direct radiative effect is almost a linear function of aerosol concentration for a given cloud cover, nonlinearities could be introduced by the change in time of the relative position of clouds and aerosols. The first indirect effect is non-linear, starting with the relationship between cloud droplet number concentration (CDNC) and aerosol concentration. In global models, this relationship may be described using empirical parameterizations that specify the CDNC as a function of the aerosol mass density (Boucher and Lohmann, 1995; Lohmann and Feichter, 1997; Roefols et al., 1998) or the aerosol number concentration (Jones et al., 1994; Menon et al., 2002; Suzuki et al., 2004), or using physically-based parameterizations (Chuang et al., 1997; Abdul-Razak and Ghan, 2002; Nenes and Seinfeld, 2003) in which the CCN activation and the droplets formation processes are described prognostically. In all cases, aerosol temporal variability will modify the first indirect effect estimation through the non-linearity of the different parametrisations. Other non-linearities influence the calculation of the first indirect effect, such as the relationship between cloud droplet size and cloud droplet number or between cloud optical thickness and cloud droplet size.

Several modelling groups have included interactive aerosols in their model and have performed many studies with this model configuration (e.g. Jones et al., 2001; Reddy et al., 2005; Roeckner et al., 2006). But, to our knowledge, none of these studies include on-line radiative forcing calculation taking into account the aerosol temporal variability. In effect, estimating radiative forcing with such a model configuration is not obvious and needs complex technical development. This limit leads several research groups to elaborate alternatives to the radiative forcing concept: the "radiative perturbation" (Penner et al, 2006); the "quasi-forcing" (Rotstayn and Penner, 2001), the " fixed SST forcing" (Hansen et al., 2002) and the "forcing with stratosphere and troposphere adjustment" (Shine et al., 2003). Lohmann et al. (2010) have evaluated such alternatives compared to radiative forcing. However, radiative forcing is a powerful diagnostic tool for studying climate perturbations. Then, we propose here to tackle this issue and elaborate solutions to compute traditional radiative forcing.

To simplify analyses and focus on the introduction of aerosol temporal variability, aerosol/cloud interactions are treated in a simple way: only sulfate is considered in this paper and we used an empirical formula for the activation parameterisation. The methods presented in this paper are not valid for models using a mechanistic activation scheme. They are also not suited to analyse radiative forcing that directly impacts meteorological fields like the cloud lifetime effect or the semi-direct effect.

After a brief presentation of LMDZ GCM features and the aerosol parameterization in the model, a description of the main choices concerning the implementation of aerosol concentrations and radiative effects (Sect. 2) is given. In Sect. 3, weaknesses, strengths and estimates are presented for the two main methods used until now to account for direct and first indirect effects in the LMDZ GCM. We also propose an estimate of the change in short-wave net fluxes due to aerosol temporal variability. In the last part of the paper, we address the question of computing radiative forcing in a coupled model. Two solutions to perform simultaneously radiative forcing calculation with interactive chemistry are proposed. We discuss their strengths and weaknesses considering their technical performance and their accuracy concerning radiative forcing estimates.

\section{Methodology}

\subsection{Model description}

In this study, we used the Laboratoire de Météorologie Dynamique general circulation model LMDZ (Hourdin et al., 2006) with a resolution of $3.75^{\circ}$ in longitude, $2.5^{\circ}$ in latitude and 19 hybrid sigma coordinate levels extending from the surface up to $3 \mathrm{hPa}$. Climatological sea surface temperatures and sea-ice fractions are used as boundary conditions to the model.

The dynamical part of the LMDZ code is based on a finitedifference formulation of the transport primitive equations and resolves the large-scale advection every six minutes. 
The physical part of the model includes the most relevant subgrid-scale physical processes such as the turbulent mixing in the boundary layer, and is computed with a time step of thirty minutes. Deep convection is parameterized using the Emmanuel scheme (1991). Clouds are represented through a log-normal probability distribution function of subgrid scale total (vapor and condensed) water (Bony and Emmanuel, 2001). Effects of mountains (drag, lifting, gravity waves) are accounted for using state-of-the-art schemes (Lott, 1999). The land surface processes are parameterised through a bucket model. Radiative transfer is calculated using a two-stream approximation, dividing the radiation in an upwelling and a downwelling flux. The parameterization is based on the scheme of Fouquart and Bonnel (1980) in the solar spectrum (SW) and on an updated version of Morcrette (1991) in the terrestrial part.

The direct and first indirect aerosol effects are included in LMDZ radiative calculations in the SW spectrum following closely the work of Quaas et al. (2004) with minor modifications.

To facilitate the analysis, this study focused on the sulfate component of the aerosol. The optical thickness, $\tau_{\mathrm{a}}$, single scattering albedo, $\omega_{\mathrm{a}}$, and particle asymmetry parameter, $g_{\mathrm{a}}$, are used by the radiative code to derive the direct effect. A Mie scattering model with the refractive index of Toon et al. (1976) for ammonium sulfate was used to compute the sulfate optical properties of each aerosol, mode taking into account aerosol size distribution. For the particles in the soluble mode, we used the hygroscopic growth factors of Martin et al. (2004) to account for the change in particle diameters due to water absorption.

The first indirect effect depends on the cloud optical thickness which varies with cloud droplet size and number. In the model, cloud optical thickness is parameterised in terms of cloud droplet effective radius $\left(r_{\mathrm{e}}\right)$ and of the cloud liquid water path $(W)$, in each layer (Stephens, 1978):

$\tau=\frac{3}{2} \frac{W}{r_{\mathrm{e}} \rho_{\text {water }}}$

The cloud droplet effective radius, $r_{\mathrm{e}}$, is related to the volume-mean cloud droplet radius $\left(r_{\mathrm{d}}\right)$ in our model by the relationship: $r_{\mathrm{e}}=1.1 r_{\mathrm{d}}$, and the volume-mean cloud droplet radius for liquid water clouds is calculated assuming spherical particles:

$r_{\mathrm{d}}=\sqrt[3]{\frac{q_{1} \rho_{\text {air }}}{\frac{4}{3} \Pi \rho_{\text {water }} N_{\mathrm{d}}}}$

where $q_{1}$ is the cloud liquid water mixing ratio, $\rho_{\text {air }}$ is the air density, $\rho_{\text {water }}$ is the density of liquid water, and $N_{\mathrm{d}}$ is the cloud droplet number. $N_{\mathrm{d}}\left(\mathrm{cm}^{-3}\right)$ is diagnosed from sulfate mass concentration, $m_{\mathrm{S}}\left(\mu \mathrm{g}\left(\mathrm{SO}_{4}\right) \mathrm{m}^{-3}\right)$, using the empirical formula of Boucher and Lohmann (1995) (formula " $D$ ").

$N_{\mathrm{d}}=10^{a_{0}+a_{1} \log \left(m_{\mathrm{a}}\right)}$

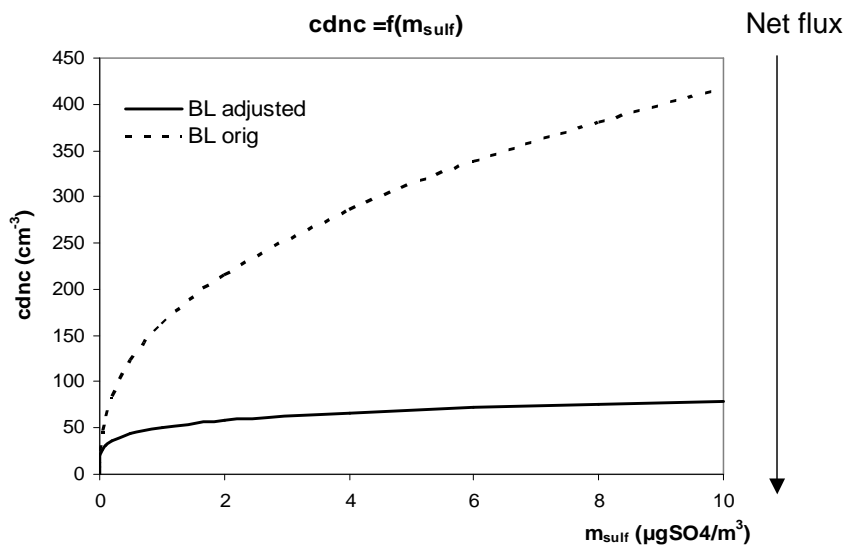

Fig. 1. Relationship between clouds droplet number $\left(\mathrm{cm}^{-3}\right)$ and the sulfate concentrations $\left(\mu \mathrm{g} \mathrm{SO}_{4} \mathrm{~m}^{-3}\right)$ from the Boucher and Lohmann (1995) D formula, with the original empirical constant (dashed) and with the adjusted empirical constant of Quaas and Boucher (2005) (solid line).

We replace the original values of the empirical constants ( $a_{0}=2.21$ and $\left.a_{1}=0.41\right)$ by the re-adjusted values from Quaas and Boucher (2005) who used POLDER space instrument retrievals $\left(a_{0}=1.7\right.$ and $\left.a_{1}=0.2\right)$. Figure 1 presents the "Boucher and Lohman" parameterisation for both the original and newer sets of empirical constants. With these new constants, the cloud droplet number sensitivity to aerosol optical depth perturbation is quite well represented in LMDZINCA compared to the observation (Quaas et al., 2009). To avoid unrealistic droplet number concentrations, especially in regions of small sulfate concentrations, $N_{\mathrm{d}}$ is restricted to be within a range from 20 to 1000 droplets per $\mathrm{cm}^{-3}$.

\subsection{Aerosol concentrations}

The LMDZ model has been used in two different configurations that only differ by the way aerosol concentration is considered: prescribed in one case (off-line configuration) and coupled with the INCA chemistry model in the other case (on-line configuration).

\subsubsection{Aerosol off-line configuration}

In the first configuration, referred to as "aerosol off-line", the aerosol concentration fields are prescribed with a given frequency (month, day...). These concentration fields have been computed and have been stored from previous simulations, including the transport and chemistry of aerosols and gases (see below). This method has been implemented in several GCM (IPCC, 2001) and has been used in many studies (e.g. Haywood et al., 1997; Mitchell and Johns, 1997; Boer et al., 2000; Dai et al., 2001; Dufresne et al., 2005). This method was initially implemented in LMDZ by Quaas et al. (2004) and by default the sulfate concentrations are prescribed monthly. The "instantaneous radiative forcing" 
(Hansen et al., 1997) is easy to estimate: one needs to compute the radiative fluxes two times at each time, one with perturbed aerosol concentration and one with reference aerosol concentration. The radiative forcing is the difference between these two radiative fluxes.

\subsubsection{Aerosol on-line configuration}

In this configuration, referred as "aerosol on-line", the chemistry processes, the aerosol concentration and the meteorological variables are fully coupled at each time step (30 min). The meteorological trajectory is influenced by sulfate concentration and the sulfur chemistry is influenced by the meteorological variables. The chemistry model is the Interaction with Chemistry and Aerosols (INCA); it consists of the sulfur cycle scheme (Schulz, 2007) and the $\mathrm{CH}_{4}-\mathrm{NO}_{\mathrm{x}}-\mathrm{CO}-$ $\mathrm{O}_{3}$ chemical scheme describing the background chemistry of the troposphere (Hauglustaine et al., 2004). Sulfate concentration and size distribution are calculated at each time step by integrating surface and in-situ emissions, wet and dry deposition processes (Schulz et al., 1998; Guelle et al., 1998a, b), humidity growth (Gerber, 1985), chemical reactions (Boucher et al., 2002) and transport. The chemical transformation of the gaseous sulphur species requires oxidants either in the gas-phase or in the liquid-phase. The sulfur chemistry implemented in INCA is similar to the one described in Boucher et al. (2002). The oxidant fields are estimated in INCA as part of the dynamic chemistry scheme. DMS and its product DMSO are oxidised using the actual concentrations of $\mathrm{OH}$ and $\mathrm{NO}_{3} . \mathrm{SO}_{2}$ is transformed to sulfate by $\mathrm{H}_{2} \mathrm{O}_{2}$ and $\mathrm{O}_{3}$ in cloud liquid water. The formation of sulfate is limited by the acidity formed in the oxidation process within cloud droplets. $\mathrm{SO}_{2}$ is also oxidised in the gas-phase. Gaseous $\mathrm{H}_{2} \mathrm{~S}$ and aerosol methane sulphonic acid (MSA) are also included as minor species of the sulphur cycle. The mass of sulfate produced through these reactions is directly injected into the soluble accumulation mode. The nucleation mode is not treated explicitly, hence, there is no new particle formation in this size range and the very fine particles are not represented. The mass median diameter (MMD) of sulfate depends upon the mixing of the ratio of sulfate formation from clouds and via gas phase oxidation. Furthermore, the MMD varies as deposition takes place since large particles will be preferentially scavenged by sedimentation and below cloud scavenging.

\subsection{Forcings}

The study has been done for the present-day period (perturbed conditions) and radiative forcing is assessed relative to the preindustrial one (unperturbed condition). Sulfate, $\mathrm{SO}_{2}$ and DMS emissions come from the AEROCOM project emissions inventory (http://aerocom.met.no/Welcome.html) (Dentener et al., 2006). Natural emissions (DMS from ocean; sulfate and $\mathrm{SO}_{2}$ from volcanoes) are kept unchanged between preindustrial and present-day periods. Only anthropogenic emissions are modified.

The aerosol concentrations fields computed in the on-line simulations are averaged and used in the off-line runs. This ensures that in both on-line and off-line simulations, the monthly mean aerosol concentration are exactly the same.

Each simulation presented in the paper consists of a tenyear snap-shot including one spin-up year. The last nine years of each simulation are used for the radiative fluxes analysis. This nine-year duration allows reducing the noise due to internal model variability compared to the effect of anthropogenic forcing.

\section{The radiative impact of aerosols and the effect of the temporal variability}

In this section, the radiative forcing or aerosol radiative effect are presented for both the on-line and off-line configuration of the model. Table 1 details the setup used for each experiment presented in this paper using these two methods. The global values of these estimates are compared, as well as their geographical distributions. Then, we analyse the effect of the temporal variability of sulfate concentrations on radiative net fluxes.

\subsection{Aerosol computed on-line}

Two simulations have been performed using the "aerosol online" configuration of the model. They differ only by the $\mathrm{SO}_{2}$ emissions. For both simulations, greenhouse gas concentrations, sea surface temperature (SST) and sea ice fraction are fixed to present-day conditions. For gaseous chemistry, reactive gas emissions are kept to their 2000 levels. In the first simulation, natural plus preindustrial $\mathrm{SO}_{2}$ emissions are used whereas in the second simulation, natural plus present-day anthropogenic emissions are used. Below, we will refer to the preindustrial fields of the first simulation with the subscript "PI" and the present-day fields with the subscript "PD".

The radiative perturbation $\left(\Delta F_{\mathrm{V}}\right)$ of anthropogenic sulfate is computed as the difference of short-wave net fluxes $\left(F_{\mathrm{V}}\right)$ at the top of the atmosphere between the present-day and the preindustrial aerosol emissions (the subscript " $\mathrm{V}$ " indicates that fluxes have been computed including the instantaneous variability of aerosol concentrations).

$\Delta F_{\mathrm{V}}=F_{\mathrm{V} \_ \text {PD }}-F_{\mathrm{V} \_ \text {PI }}$

This radiative perturbation differs from an instantaneous radiative forcing because present-day and preindustrial net fluxes are estimated for two different atmospheric trajectories after the atmospheric column (troposphere and stratosphere) has had time to adjust. It is identical to the "fixed SST radiative forcing" defined by Hansen et al. (2002). This diagnostic tool includes both direct and first indirect effects. With this model version, it is not possible to study each effect separately. Fluxes include the two effects. 
Table 1. Description of the experiments presented in this paper. The first column specifies which sulfate fields are used to drive the meteorological trajectory of the simulation; the 2nd and 3rd columns describe the type of aerosol used to calculate net fluxes at the top of the atmosphere and radiative forcing. The last column specifies the time step at which the radiative forcing is computed from radiative net fluxes. PD refers to present-day, PI to preindustrial.

\begin{tabular}{|c|c|c|c|c|c|}
\hline & & $\begin{array}{l}\text { meteorological } \\
\text { trajectory driver }\end{array}$ & $\begin{array}{l}\text { PD sulfate } \\
\text { concentration }\end{array}$ & $\begin{array}{l}\text { PI sulfate } \\
\text { concentration }\end{array}$ & $\begin{array}{l}\text { RF time step } \\
\text { calculation }\end{array}$ \\
\hline \multicolumn{2}{|l|}{$\mathrm{CM}_{\text {Offline }}$} & $\begin{array}{l}\text { PD monthly mean sulfate } \\
\text { computed off-line }\end{array}$ & $\begin{array}{l}\text { Prescribed at } \\
\text { monthly time step }\end{array}$ & $\begin{array}{l}\text { Prescribed at } \\
\text { monthly time step }\end{array}$ & $30 \mathrm{~min}$ \\
\hline \multirow[t]{2}{*}{ CM-Online } & $\begin{array}{l}\text { Present-day } \\
\text { simulation }\end{array}$ & $\begin{array}{l}\text { PD fully-variable sulfate } \\
\text { computed on-line }\end{array}$ & Computed on-line & & \\
\hline & $\begin{array}{l}\text { Preindustrial } \\
\text { simulation }\end{array}$ & $\begin{array}{l}\text { PI fully-variable sulfate } \\
\text { computed on-line }\end{array}$ & & Computed on-line & \\
\hline \multirow[t]{2}{*}{$\mathrm{M}_{\mathrm{REF}}$} & $\begin{array}{l}\text { Present-day } \\
\text { simulation }\end{array}$ & $\begin{array}{l}\text { PD fully-variable sulfate } \\
\text { computed on-line }\end{array}$ & Computed on-line & & \multirow{2}{*}{ monthly } \\
\hline & $\begin{array}{l}\text { Preindustrial } \\
\text { simulation }\end{array}$ & $\begin{array}{l}\text { PD fully-variable sulfate } \\
\text { computed offline }\end{array}$ & & Computed on-line & \\
\hline \multicolumn{2}{|l|}{ M Offline_ext } & $\begin{array}{l}\text { PD fully-variable sulfate } \\
\text { computed on-line }\end{array}$ & Computed on-line & $\begin{array}{l}\text { Prescribed at } \\
\text { monthly time step }\end{array}$ & $30 \mathrm{~min}$ \\
\hline \multicolumn{2}{|c|}{ MOffline_ext_corr } & $\begin{array}{l}\text { PD fully-variable sulfate } \\
\text { computed on-line }\end{array}$ & Computed on-line & $\begin{array}{l}\text { Prescribed at } \\
\text { monthly time step }\end{array}$ & $\begin{array}{l}30 \text { min + monthly } \\
\text { correction }\end{array}$ \\
\hline
\end{tabular}

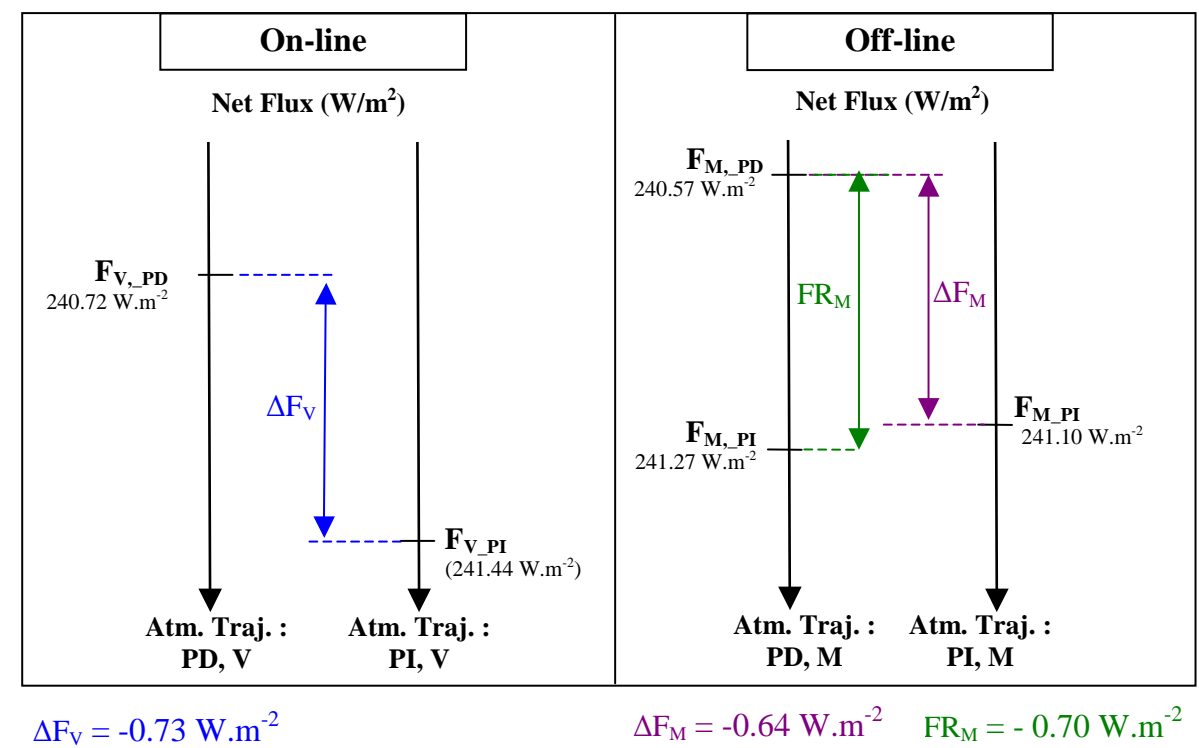

Fig. 2. Representation of the radiative perturbation $(\Delta F)$ and radiative forcing (RF) calculated from simulations performed with the on-line and off-line model configuration. For each case, both axes indicate that the fluxes are obtained for two different atmospheric model trajectories depending on the sulfate concentration: present-day or preindustrial ones. For the on-line configuration, the "V" annotation indicates that variable sulfate concentrations are used; as the "M" annotation referred to monthly mean concentration for the off-line configuration.

Values of $F_{\mathrm{V} \_P D}, F_{\mathrm{V} \_P I}$ and $\Delta F_{\mathrm{V}}$ are indicated in Fig. 2. The global annual mean value of the radiative perturbation is $-0.73 \mathrm{~W} \mathrm{~m}^{-2}$.

If we focus now on the geographical distribution of this radiative perturbation, the pattern that one may expect from the aerosol geographical distribution is not discernable and the figure shows a noisy pattern (Fig. 3). This signal is due to natural variability. The mean cloud distributions of the two simulations are slightly different due to internal variability and this difference strongly impacts the radiative fluxes at the top of the atmosphere. The signal/noise ratio could be improved with long simulations of a hundred years, but the computing 


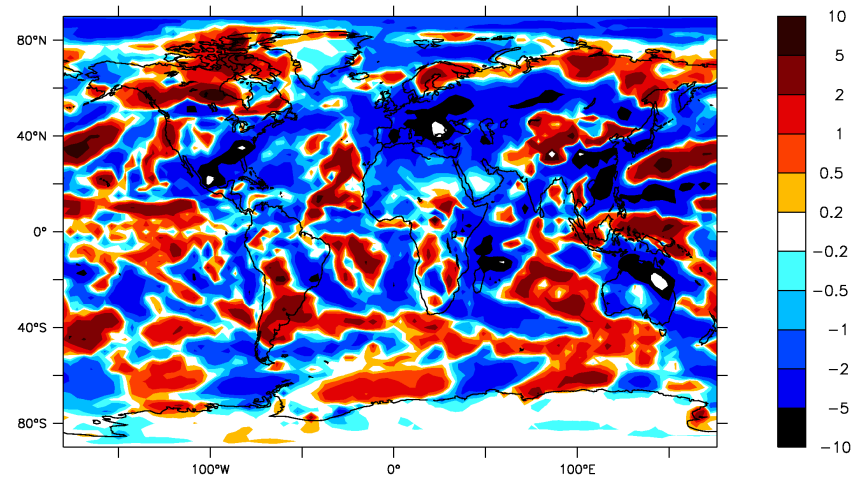

Fig. 3. Difference between the short wave top-of-atmosphere net fluxes (in $\mathrm{W} \mathrm{m}^{-2}$ ) computed with present day and with preindustrial sulfate emissions. The on-line configuration of the model is used.

time for the chemistry-aerosol module is prohibitive for such long runs.

\subsection{Aerosol computed off-line}

The same two simulations have been performed using the off-line configuration of the model. The prescribed aerosol concentrations are kept constant during each month and are set to the monthly mean value of the aerosol concentrations previously obtained with the on-line simulations. This ensures that in both on-line and off-line simulations, the monthly mean aerosol concentrations are exactly the same. The fluxes computed with prescribed monthly mean aerosol concentration have the subscript " $M$ ".

Figure 2 compares the shortwave net fluxes of the offline configuration ( $F_{\mathrm{M} P \mathrm{PD}}$, and $\left.F_{\mathrm{M} \text { PI }}\right)$ to those of the online simulation $\left(F_{\mathrm{V}_{-} \mathrm{PD}}\right.$ and $\left.F_{\mathrm{V} \_ \text {PI }}\right)$. With this configuration, the radiative perturbation $\left(\Delta F_{\mathrm{M}}\right)$ amounts to $-0.64 \mathrm{~W} \mathrm{~m}^{-2}$. It is $12 \%$ higher than the value obtained when sulfate concentration is computed on-line $\left(-0.73 \mathrm{~W} \mathrm{~m}^{-2}\right)$. In addition, the off-line configuration allows us to easily compute the radiative forcing of aerosols for both the direct and indirect effect of the aerosol (e.g. Quaas et al., 2004). The total radiative forcing (sum of direct and first indirect effects) amounts to $-0.70 \mathrm{~W} \mathrm{~m}^{-2}$. It is close to the radiative perturbation $\left(\Delta F_{\mathrm{M}}=-0.64 \mathrm{~W} \mathrm{~m}^{-2}\right)$. This result is consistent with Hansen et al. (2002), who obtained that the radiative perturbation for fixed SST is close to the instantaneous radiative forcing for non-absorbing aerosols such as sulfate.

The direct effect value is $-0.31 \mathrm{~W} \mathrm{~m}^{-2}$, whereas the indirect effect reaches $-0.39 \mathrm{~W} \mathrm{~m}^{-2}$. The simulated direct radiative forcing is very close to the mean value derived in the AEROCOM project of $-0.35 \pm 0.15 \mathrm{~W} \mathrm{~m}^{-2}$ (Schulz et al., 2006). This value also lies inside the $90 \%$ confidence interval $\left(-0.4 \pm 0.2 \mathrm{~W} \mathrm{~m}^{-2}\right)$ reported in the 4 th IPCC assessment report (Forster et al., 2007). The first indirect radiative forcing straddles the lowest part (in absolute value) of the val- (o) direct effet

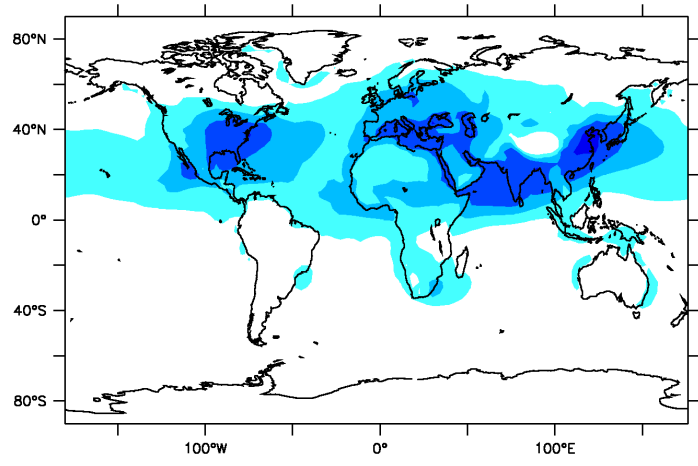

(b) first indirect effect

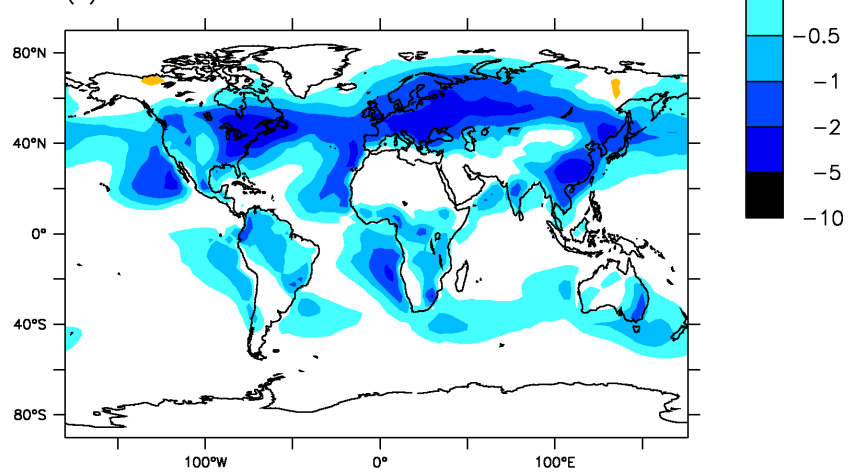

Fig. 4. Radiative forcings $\left(\mathrm{W} \mathrm{m}^{-2}\right)$ estimated with the off-line configuration of the model for present-day, sulfate emissions: (a) direct effect (b) 1 st indirect effect.

ues reported in the 4 th IPCC report $\left[-0.2\right.$ to $\left.-1.9 \mathrm{~W} \mathrm{~m}^{-2}\right]$ (Forster et al., 2007). This low value of the first indirect effect comes mainly from the use of new constants $a_{0}$ and $a_{1}$ in the Boucher and Lohmann microphysics relationships (Eq. 3). Quaas and Boucher (2005) showed that with their set of constants, simulated cloud droplet number decreases and the first indirect effect radiative forcing is divided by a factor 2. Dufresne et al. (2005) corroborate this finding in a study on climatic impact of sulfate aerosol performed with the IPSL coupled model that also shows the importance of low level clouds over continents.

Figure 4 shows the direct and first indirect aerosol radiative forcing. As expected, sulfate results in a cooling of the surface and displays a very heterogeneous distribution. The direct radiative forcing is strongly correlated to the emission sources. Values up to $-5 \mathrm{~W} \mathrm{~m}^{-2}$ can be reached in some industrial regions. The patterns of the first indirect effect are correlated to both emission sources and cloud cover. Some regions in north latitudes show a positive first indirect effect. It comes from a decrease of $\mathrm{SO}_{2}$ emissions by biomass burning between present-day and preindustrial periods. 


\subsection{Effect of the sulfate temporal variability on the radiative fluxes}

The radiative net fluxes of the on-line and off-line simulations may differ because of the frequency at which aerosol concentrations vary (prescribed every month in one case, computed every time step in the other case) but also because of the different meteorological trajectory between the two simulations. In the off-line method, the meteorological trajectory is influenced by the monthly mean sulfate concentration, whereas in the on-line method, the meteorological trajectory responds to the effect of instantaneous concentrations (Fig. 2).

In this part of the study, the effect of the aerosol temporal variability has been isolated from the effect of the meteorological trajectories and then analysed.

\subsubsection{Method}

The effect of the temporal variability is studied by comparing two simulations which only differ by the frequency at which the sulfate concentration is updated: every model time step (30 min) for the simulation is referred to as "VAR simulation" and every month in the case of the simulation is referred to as "MONTH simulation". The average concentrations fields and the meteorological trajectory are the same for the 2 simulations; therefore the difference in the mean aerosol distribution can not be the reason of the difference between off-line and on-line runs.

For the VAR simulation, the aerosols are computed online as presented in Sect. 3.1. The MONTH simulation is run off-line with respect to the meteorological trajectory of the VAR simulation (temperature, pressure, wind, humidity, cloud fraction, LW path,...). Then, the only difference in the MONTH simulation comes from the use of monthly sulfate concentrations that are used to compute aerosol and cloud radiative properties and radiative fluxes.

Two sets of VAR and MONTH simulations have been performed for present-day and preindustrial sulfate emissions. Preindustrial simulations have also been performed off-line with respect to the meteorological trajectory that is based on the present-day, fully-variable, sulfate aerosol retroaction. Then, the meteorological trajectory is exactly the same in the preindustrial and in the present-day simulations. The only difference is the anthropogenic emission of sulfate aerosols. We examine the change in net fluxes at the top-ofatmosphere between the experiments VAR and MONTH for the present day $\left(F_{\mathrm{V} \text { PD }}-F_{\mathrm{M} \text { PD }}\right)$ and the preindustrial periods $\left(F_{\mathrm{V} \_ \text {PI }}-F_{\mathrm{M} \_ \text {PI }}\right)$. Net fluxes are computed each $30 \mathrm{~min}$ and monthly averaged for each simulation. Differences between the VAR and MONTH experiments are calculated from these monthly mean net flux values. The net fluxes resulting from this experiment are schematically presented in Fig. 5. The effect of the meteorological trajectory is null.

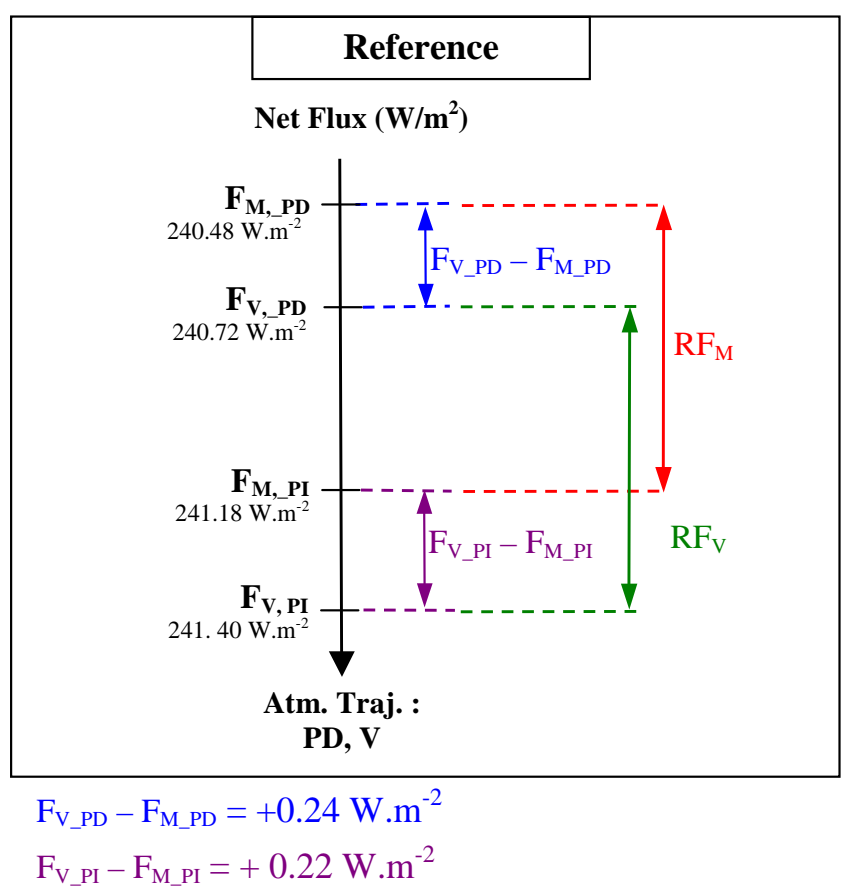

Fig. 5. Representation of the difference of radiative net fluxes calculated between the VAR (sulfate concentration computed each 30 min with INCA) and the MONTH (sulfate concentration prescribed each month) experiments. All simulations have been performed with the same physical forcings in order to get exactly the same meteorological trajectory: the present-day one with sulfate variability.

\subsubsection{Global and regional results}

Figure 5 indicates the values of the shortwave net fluxes at the top-of-atmosphere for the two simulations VAR and MONTH and for the two periods. Globally, temporal variability of sulfate concentration increases these net fluxes by $+0.24 \mathrm{~W} \mathrm{~m}^{-2}$ for the present-day conditions and by $+0.22 \mathrm{~W} \mathrm{~m}^{-2}$ for the preindustrial ones. The regional distribution of this change for present day and preindustrial conditions is shown in Fig. 6; the impact of the direct effect (Fig. 6a and b) and the first indirect effect (Fig. 6c and d) are separated. With the exception of a few model grid points, the temporal variability leads to an increase of the total net fluxes (direct and first indirect effects) at the top of atmosphere for the two periods: preindustrial and present day. The changes in total net fluxes are within the interval -0.5 and $+2.5 \mathrm{~W} \mathrm{~m}^{-2}$. However, as it is shown in Fig. 6a and b, the direct effect has a negligible role, it tends to slightly decrease net fluxes. The increase of net fluxes results mainly from the first indirect effect. More precisely, this increase is linked to the shape of the relationship between the number concentration of cloud droplet $N_{\mathrm{d}}$ and the sulfate concentration $m_{\mathrm{s}}$. Consider $N_{\mathrm{d}, \mathrm{M}}$ to be the number concentration of droplets corresponding to the average sulfate concentration 
a) Direct effect - Present-day period

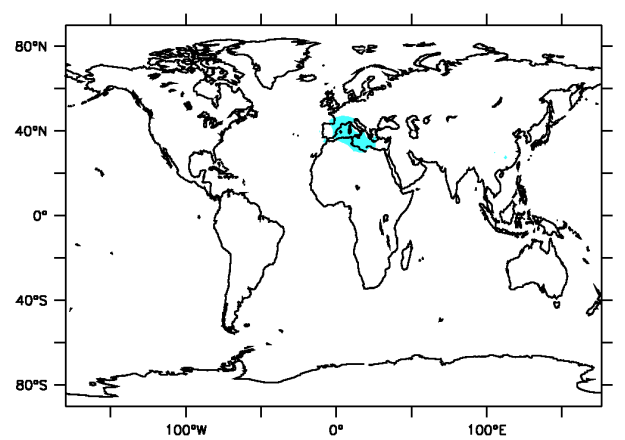

b) Direct effect - Preindustrial period

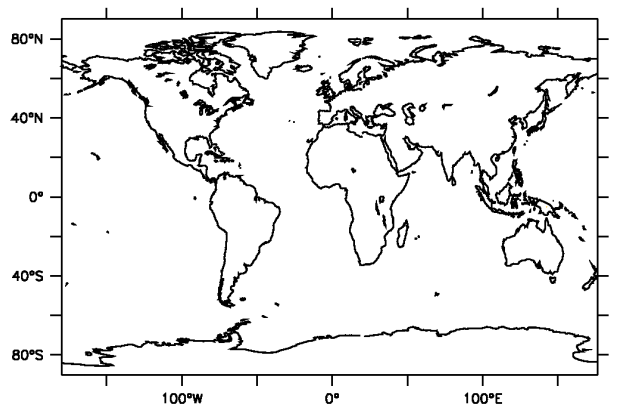

c) First indirect effect - Present-day period

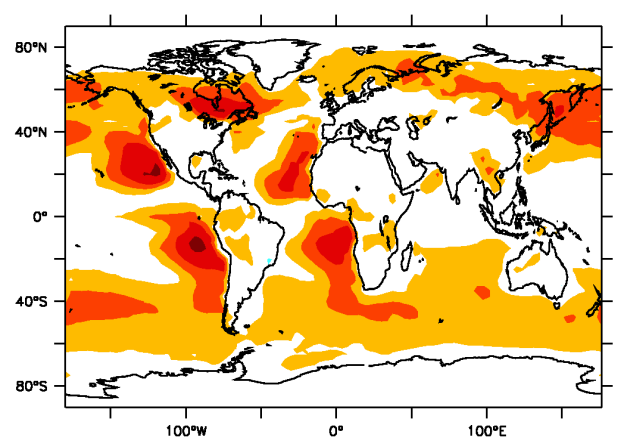

10
5
2
1
0.5

0.2

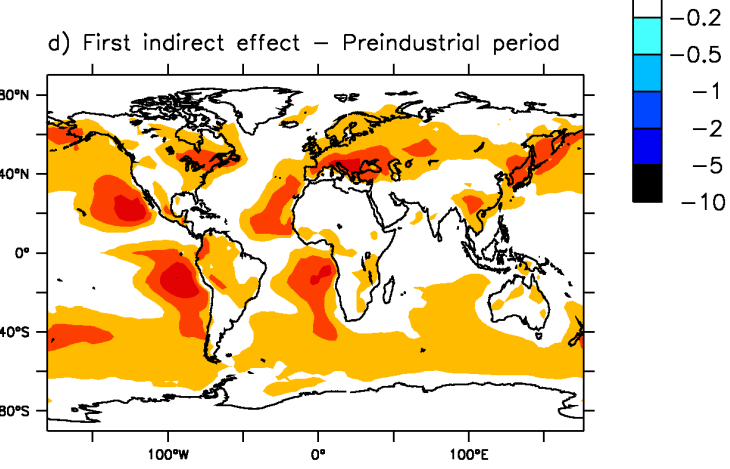

Fig. 6. Difference of the top-of-atmosphere fluxes $\left(\mathrm{W} \mathrm{m}^{-2}\right)$ between the simulation in which the aerosol concentration varies at each time step (VAR experiment) and the simulation in which the concentration remains constant, prescribed to the monthly mean values (MONTH experiment) for present day sulfate emissions (top) and preindustrial sulfate emission (below). Impact of the sulfate first indirect effect (left) and the sulfate direct effect (right) are presented separately.

in the MONTH experiment. By construction, this value stays unchanged throughout the month. Let's consider now, $N_{\mathrm{d}, \mathrm{V}}$, the number concentrations obtained from the instantaneous sulfate concentrations in the VAR experiment. Because this relationship grows asymptotically when sulfate concentration increases, the monthly mean of $N_{\mathrm{d}, \mathrm{V}}$ values will be less than the $N_{\mathrm{d}, \mathrm{M}}$ value. Since net fluxes decrease when the number of cloud droplets increases, the monthly mean net fluxes computed in the experiment VAR, $F_{\mathrm{V}}$ is greater than the average net fluxes $F_{\mathrm{M}}$ computed from the monthly mean sulfate concentration.

\subsubsection{Analysis}

Three main variables contribute to the radiative effect of aerosol: the fraction of low level clouds, their liquid water content, and the sulfate concentration. Figure 7 displays the cloud liquid water content and the percentage of the liquid water from low-level clouds. The presence of low clouds shows the same pattern as the changes in fluxes at the top of the atmosphere caused by the variability of sulfate concentrations (Fig. $6 \mathrm{c}$ and d). In upwelling regions the change in flux at the top of the atmosphere reaches 1 to $2.5 \mathrm{~W} \mathrm{~m}^{-2}$ in present-day conditions. Coastal regions west of South and North America together with coastal regions west of Africa are more affected than others by the variability of aerosol concentrations. In contrast, over Indonesia and India, the impact of the sulfate temporal variability is weak even though the liquid water content is much higher than over the other regions discussed. In these areas, clouds are situated at much higher altitudes (Fig. 7b). Finally, above dry regions without clouds, there is no indirect effect and hence no effect of the sulfate concentration's variability.

The time average value of the sulfate concentration is shown in Fig. 8. Regions with low to intermediate sulfate concentration appear to be more sensitive to the aerosol temporal variability than regions with high sulfate concentration. This effect can be seen over Europe, for instance. Net fluxes differ substantially in preindustrial conditions when sulfate concentrations are low (Figs. $6 \mathrm{~d}$ and $8 \mathrm{~b}$ ), whereas the difference vanishes under present- day conditions (Figs. 6c and $8 \mathrm{a})$. This effect can also be seen in South-East Asia.

The slope of the relationship between cloud droplet concentration $\left(N_{\mathrm{d}}\right)$ and sulfate concentration $\left(m_{\mathrm{s}}\right)$ of the first indirect effect (Fig. 1) explains the difference of net fluxes between polluted and unpolluted regions. In unpolluted regions a small change in sulfate concentrations corresponds to a large change in cloud droplet number, whereas in polluted regions higher-level sulfate will result in small changes in cloud droplet number. 
(a) total liquid water content $\left(\mathrm{g} / \mathrm{m}^{2}\right)$

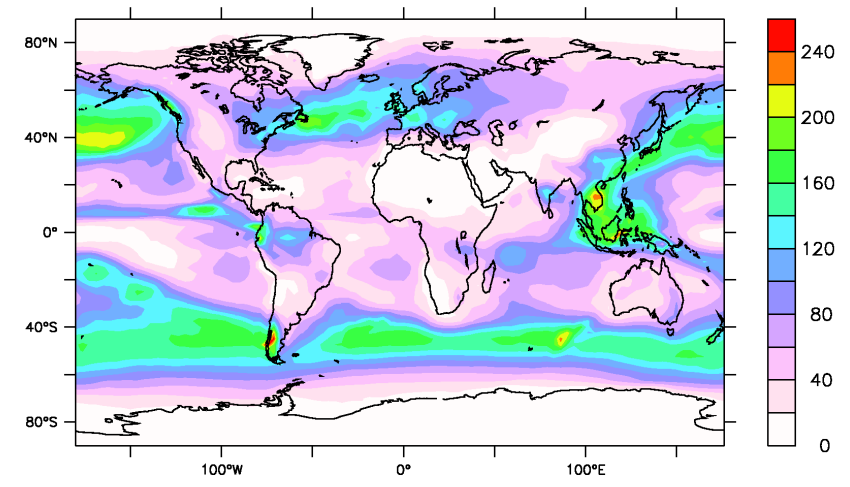

(b) low-cloud liquid water content (percentage)

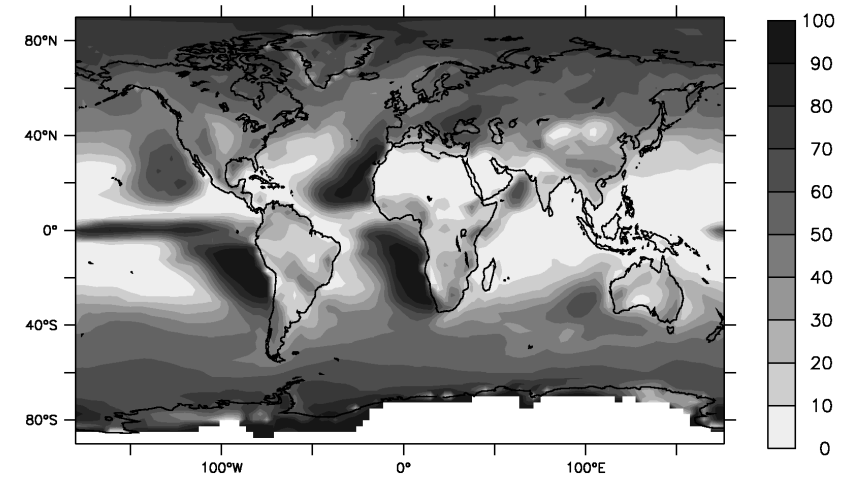

Fig. 7. (a) Cloud liquid water path $\left(\mathrm{g} \mathrm{m}^{-2}\right)$ for all the clouds and (b) percentage of this liquid water path in low level clouds $(P>$ $850 \mathrm{hPa}$ ).

We identified in our model a concentration threshold of $0.8 \mu \mathrm{g}\left(\mathrm{SO}_{4}\right) \mathrm{m}^{-3}$ above which temporal changes in sulfate concentrations have little impact on net fluxes. The regions where this threshold is exceeded are: China, Europe and the east coast of the United States which all are areas downwind of the main industrialized regions. Other regions with high sulfate are located downwind of natural volcanic emission regions. For theses concentrations levels, the aerosol temporal variability do not affect the top-of-atmosphere net fluxes.

In contrast, the effect of aerosol temporal variability is large for intermediate sulfate concentrations (between about 0.1 and $\left.0.8 \mu \mathrm{g}\left(\mathrm{SO}_{4}\right) \mathrm{m}^{-3}\right)$ over remote regions.

In regions devoid of sulfate (concentration less than $\left.0.1 \mu \mathrm{g}\left(\mathrm{SO}_{4}\right) \mathrm{m}^{-3}\right)$, the first indirect effect is close to zero. An example for such a region is South America, where the liquid water content is high, low-level clouds are abundant but sulfate levels are very small for the present day.

We chose six regions to show how different cloud and sulfate concentrations fare affected differently by sulfate temporal variability: the Pacific Ocean, the Atlantic Ocean, the southern part of South America, India, Indonesia and continental Europe (Table 2). For each region, the liquid water content, the mean sulfate concentrations for present day and (a) present-day period

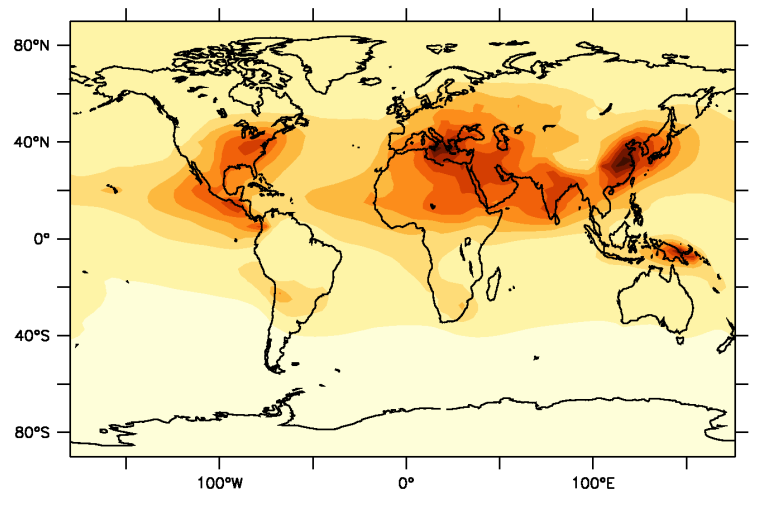

20
18
16
14
12

(b) preindustrial period

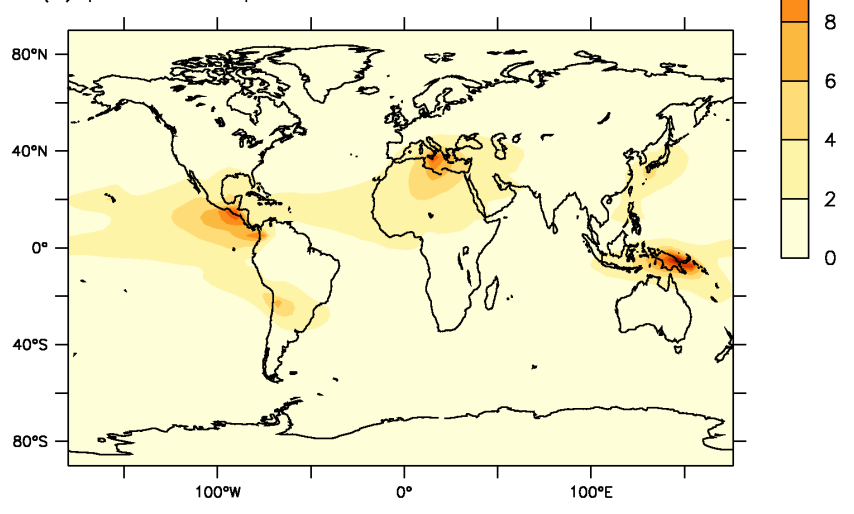

Fig. 8. Annual mean of the sulfate load $\left(\mathrm{mg}\left(\mathrm{SO}_{4}\right) \mathrm{m}^{-2}\right)$ for present day (a) and preindustrial periods (b).

preindustrial and the change in flux for present and preindustrial conditions are reported in Table 3. The comparison of preindustrial and present-day conditions confirms the sensitivity of radiative fluxes in regions of low level clouds to intermediate sulfate concentration. Vertical profiles of cloud liquid water content and preindustrial and present-day sulfate concentrations are also displayed for these six regions (Fig. 9). Intermediate levels of sulfate concentrations are reached at the height of the low-level clouds. The maximum sulfate concentration is reached above the low-level clouds' altitude. The first indirect effect shows a marked nonlinearity for these intermediate concentration levels (Fig. 1). This is one of the reasons for the strong sensitivity of the first indirect effect to the variability of sulfate in the presence of low-level clouds.

\section{Calculation of the radiative forcing for on-line simulations}

The estimate of radiative perturbation (defined in Sect. 3.1) needs very long simulations to reduce the noise due to natural variability. Thus, this approach is not suitable for transient 
Table 2. Geographical coordinates of the 6 regions that were used for the analysis shown in Fig. 7: (1) South Atlantic Ocean along the West Coast of Africa (referred as AO-WAf), (2) North Pacific Ocean along the West Coast of North America (referred as PO-WNA); (3) the southern part of South America (South Am.); (4) India (India); (5) Indonesia Islands (InIs); (6) Europe (Eu).

\begin{tabular}{lllllll}
\hline Région & WAf & WNA & Am. Sud & Inde & InIs & Eu \\
\hline Latitude & $0-35^{\circ} \mathrm{S}$ & $10-40^{\circ} \mathrm{N}$ & $37-45^{\circ} \mathrm{S}$ & $6-25^{\circ} \mathrm{N}$ & $-15^{\circ} \mathrm{S}-0$ & $35-60^{\circ} \mathrm{N}$ \\
Longitude & $20^{\circ} \mathrm{W}-15^{\circ} \mathrm{E}$ & $150-110^{\circ} \mathrm{W}$ & $66-72^{\circ} \mathrm{W}$ & $70-85^{\circ} \mathrm{E}$ & $130-165^{\circ} \mathrm{E}$ & $60-110^{\circ} \mathrm{E}$ \\
\hline
\end{tabular}

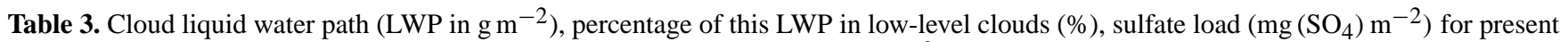
and preindustrial periods, short waves top-of-atmosphere net flux difference $\left(\mathrm{W} \mathrm{m}^{-2}\right)$ between the VAR and MONTH experiments for present $\left(\Delta \mathrm{NF}_{\mathrm{pr}}\right)$ and preindustrial $\left(\Delta \mathrm{NF}_{\mathrm{pi}}\right)$ for the 6 regions targeted in Fig. 7: (1) South Atlantic Ocean along the West Coast of Africa (referred as AO-WAf), (2) North Pacific Ocean along the West Coast of North America (referred as PO-WNA); (3) the southern part of South America (South Am.); (4) India (India); (5) Indonesia Islands (InIs); (6) Europe (Eu).

\begin{tabular}{lrrlrlc}
\hline Region & $\begin{array}{r}\mathrm{LWP} \\
\left(\mathrm{g} \mathrm{m}^{-2}\right)\end{array}$ & $\begin{array}{r}\text { \% LWP } \\
\text { low-level } \\
\text { cloud }\end{array}$ & $\begin{array}{l}\text { Present-day } \\
\text { sulfate } \\
\left(\mathrm{mg}\left(\mathrm{SO}_{4}\right) \mathrm{m}^{-2}\right)\end{array}$ & $\begin{array}{c}\Delta \mathrm{NF}_{\mathrm{pr}} \\
\left(\mathrm{W} \mathrm{m}^{-2}\right)\end{array}$ & $\begin{array}{l}\text { Preindustrial } \\
\text { sulfate } \\
\left(\mathrm{mg}\left(\mathrm{SO}_{4}\right) \mathrm{m}^{-2}\right)\end{array}$ & $\begin{array}{r}\Delta \mathrm{NF}_{\mathrm{pi}} \\
\left(\mathrm{W} \mathrm{m}^{-2}\right)\end{array}$ \\
\hline WAf & 46.3 & 69.1 & 2.5 & 0.72 & 1.2 & 0.52 \\
WNA & 71.3 & 49.7 & 4.0 & 0.84 & 1.8 & 0.63 \\
Am Sud & 125.7 & 50 & 0.74 & 0.06 & 0.49 & 0.10 \\
Inde & 61.5 & 12.4 & 9.5 & 0.05 & 1.2 & 0.09 \\
InIs & 84.3 & 4.0 & 5.5 & 0.08 & 4.9 & 0.09 \\
Eu & 74.6 & 51.6 & 6.6 & 0.05 & 1.5 & 0.43 \\
\hline
\end{tabular}

climate simulations. In addition, radiative forcing is a powerful diagnostic tool to compare the radiative impact of different perturbations (aerosol, greenhouse gases, land use...) and different aerosol types (sulfate, black carbon, organic carbon, etc). For these reasons, we propose several methods to compute aerosol radiative forcing for on-line simulations in the next section. Their relevance is discussed with respect to the computation time needed and to their precision. These methods have been developed for models using an empirical parameterization of the cloud droplet number concentration.

\subsection{A direct extension of the radiative forcing computation method used for off-line simulations}

In the aerosols' off-line configuration, the radiative forcing is simply computed as the difference, at each time step, between the radiative fluxes computed with two aerosol concentration fields: the actual concentration and a reference concentration, here chosen as the preindustrial one. These two fields are monthly mean values and remain constant during the whole month. One can directly apply this method for on-line configuration: the actual concentration is now the aerosols' concentration calculated on-line by the INCA chemistry model and then varying at each time step. The preindustrial concentration is unchanged and still prescribed to its monthly mean value. This method is called, $\mathbf{M}_{\text {offline_ext }}$, which stands for: extended off-line method (Table 1).

The modification of the direct effect due to the change of aerosol concentration between present-day and preindustrial conditions results in a difference of net fluxes at the top of the atmosphere that amounts to $-0.32 \mathrm{~W} \mathrm{~m}^{-2}$. It is very close to the value of the direct radiative forcing obtained with the offline method (-0.31 $\mathrm{W} \mathrm{m}^{-2}$, Sect. 3.2). Computing sulfates interactively increases the difference of net fluxes at the top of the atmosphere by $3 \%$ relative to the off-line method when these concentrations are read in. The geographical distribution of these two fields is also very similar (Fig. 10a and c). Industrial regions where $\mathrm{SO}_{2}$ emissions sources are located are more sensitive to the temporal variability of aerosol. The non-linearity due to the variation with time of the sulfate concentration is weak. It is consistent with the direct net flux changes analysed in Sect. 3.3

The modification of the first indirect effect due to the change of aerosol concentration between present-day and preinsustrial conditions results in a difference of net fluxes at the top of the atmosphere estimated at $-0.17 \mathrm{~W} \mathrm{~m}^{-2}$. This value differs by $60 \%$ compared to the radiative forcing obtained with the off-line method $\left(-0.39 \mathrm{~W} \mathrm{~m}^{-2}\right.$, Sect. 3.2). The geographical difference of these two fields (Fig. 10b) is positive almost everywhere, the highest values being in regions where low-level clouds are abundant (Fig. 10d). It is worth noticing that these regions are generally remote from the main $\mathrm{SO}_{2}$ source regions and therefore are found where the sulfate atmospheric load is small.

A sensitivity test has been performed in which 30 min preindustrial sulfate fields have been prescribed instead of monthly mean values. Results are very close to those of the initial extended off-line method showing that this difference 


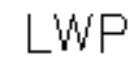

(mg $/ m-3)$
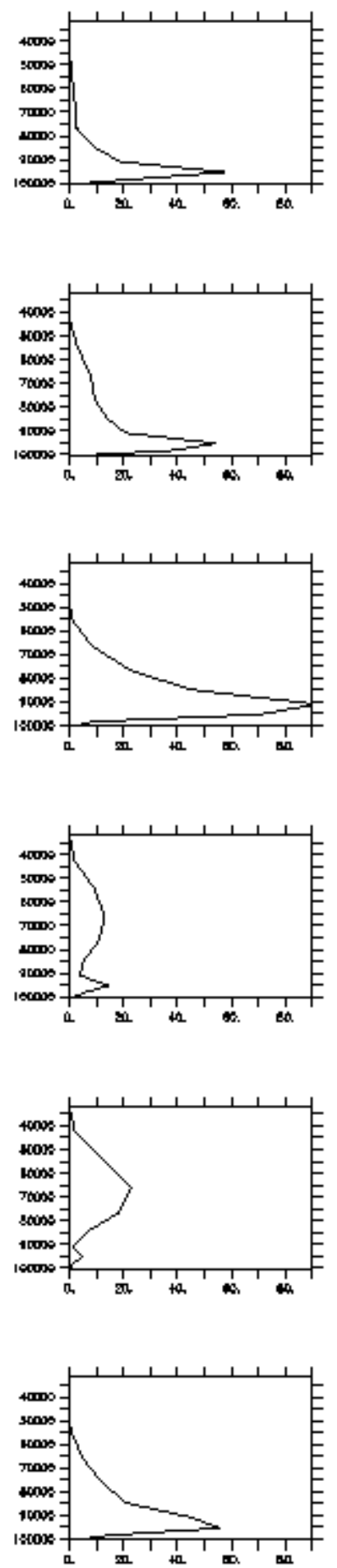

504 pres (ugs04/m-3)
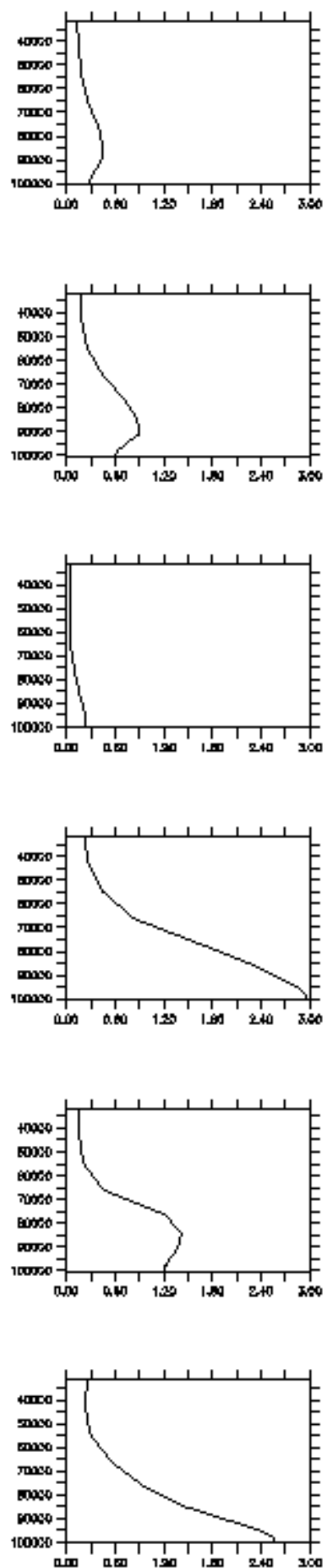

SO4 preind (w口s04/m-3)
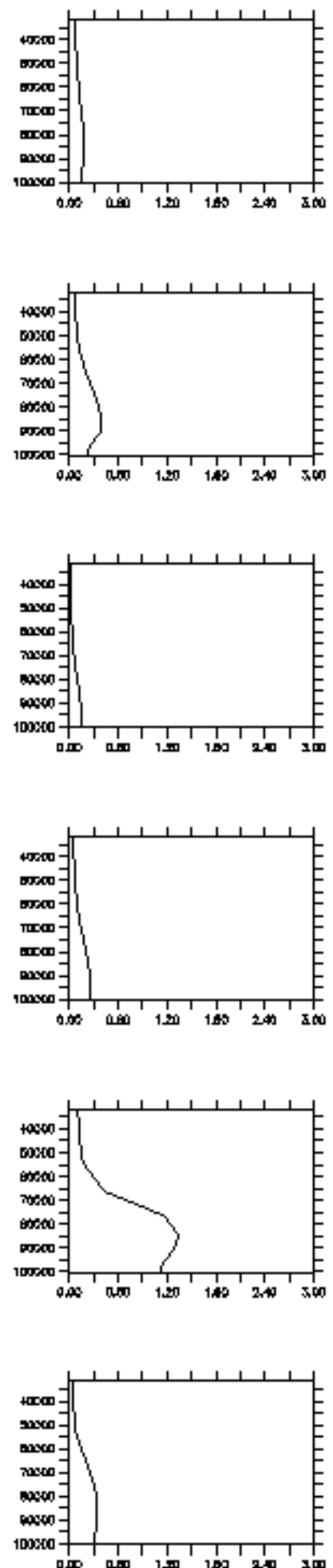

Fig. 9. Annual mean vertical profile of the cloud liquid water content $\left(\mathrm{mg} \mathrm{m}^{-3}\right)$, and of the sulfate content $\left(\mathrm{in} \mu \mathrm{g}\left(\mathrm{SO}_{4}\right) \mathrm{m}^{-3}\right)$ for present day $\left(\mathrm{SO}_{4}-\mathrm{PR}\right)$ and preindustrial emissions $\left(\mathrm{SO}_{4}-\mathrm{PI}\right) .6$ regions are considered, from top to bottom: (1) South Atlantic Ocean along the West Coast of Africa; (2) North Pacific Ocean along the West Coast of North America; (3) the southern part of South America; (4) India; (5) Indonesia Islands; (6) Europe. 
Extended off-line method

a) direct effect

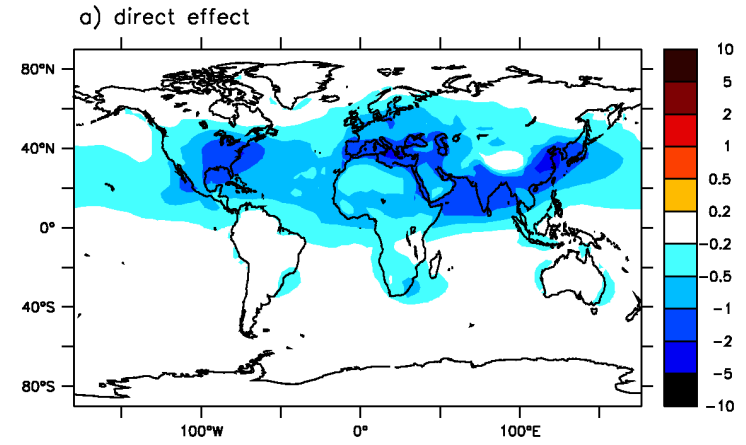

b) first indirect effect

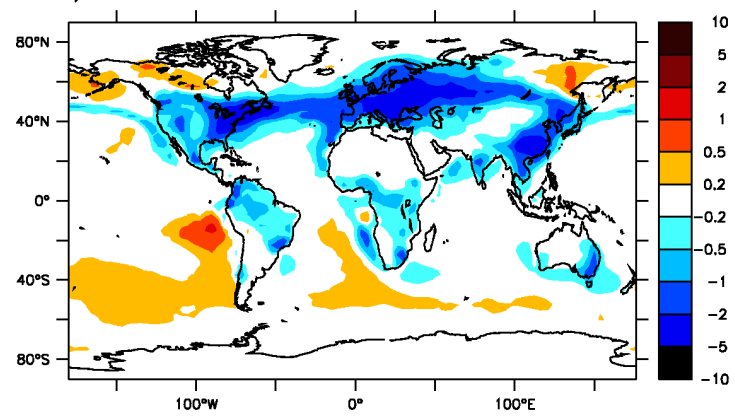

Difference between the extended off-line method and the off-line classical method
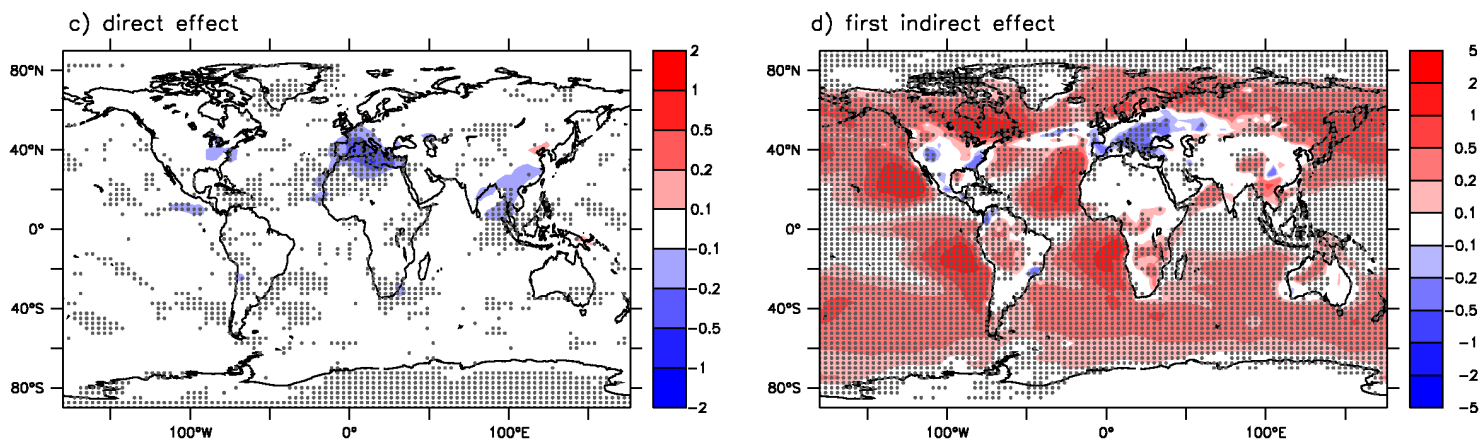

Fig. 10. Radiative forcing calculated from the extended off-line method for: (a) sulfate direct effect (W $\mathrm{m}^{-2}$ ), (b) sulfate $1 \mathrm{st}$ indirect effect $\left(\mathrm{W} \mathrm{m}^{-2}\right)$. Difference of radiative forcings between the off-line extended method and the off-line method: (c) sulfate direct effect $\left(\mathrm{W} \mathrm{m}^{-2}\right)$, (d) sulfate 1st indirect effect $\left(\mathrm{W} \mathrm{m}^{-2}\right)$. The statistical signifiance of the difference was tested at the $95 \%$ confidence level using a bootstrap method. Regions where the difference is statistically significant are indicated with dots. The scales of the top row maps are in the range $\left[-10 ;+10 \mathrm{~W} \mathrm{~m}^{-2}\right]$, whereas the values for the bottom row maps (that represent differences in radiative forcings) vary between $[-2:+2]$ or $[-5:+5] \mathrm{W} \mathrm{m}^{-2}$.

does not come from the use of monthly versus instantaneous aerosol concentrations.

Nevertheless, this simple method presents a major inconsistency: the sulfate concentration field for the present day is computed on-line in the model, varies at each time step, and is linked to the meteorology of the simulation. In contrast, the preindustrial field does not vary with time and has no link with the actual meteorology. It has been obtained off-line from a previous simulation with different transport fields, different timing for precipitation and clouds, and hence different timing for the scavenging of aerosols by clouds. This may have an important impact as the first indirect effect is strongly non-linear and the radiative forcing computed at each time step. At any given time, present day sulfate concentrations can be lower than preindustrial values, causing a positive first indirect effect estimate. These positive values of the first indirect effect would not appear if the radiative forcing was computed from month mean net fluxes instead of from the instantaneous ones.
In this simple method, the aerosol concentration difference between the preindustrial and present periods has two distinct origins: the sulfate emissions and the variability of the atmosphere. The first effect is the one that we want to estimate. The second effect is unwanted and may have a large amplitude To avoid this inconsistency, both aerosol fields need to vary with time in a consistent manner, and therefore need to be computed with the same meteorological fields.

\subsection{A reference method to compute the first indirect radiative forcing}

In order to have a reference estimate of the indirect radiative forcing for on-line simulation, we compute the aerosol concentration for present-day and preindustrial emissions with two very same meteorological trajectories. For both periods, the aerosol temporal variability is accounted for, the meteorological trajectories are the same, hence the only difference is the aerosol emission and the impact of the respective aerosol concentration fields on the radiative fluxes (Table 1). The approach is the same as the one described in Sect. 3.3.1. The simulations used here are the "VAR" experiments with 
(a) reference method

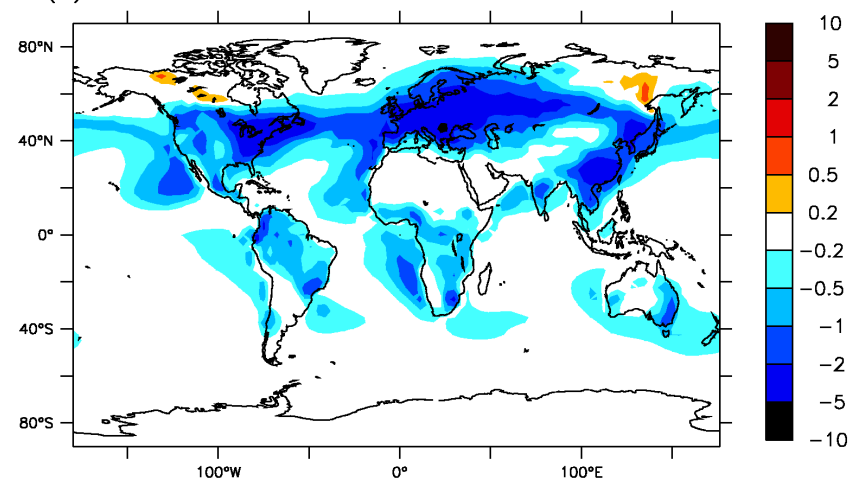

(b) reference method - offline method

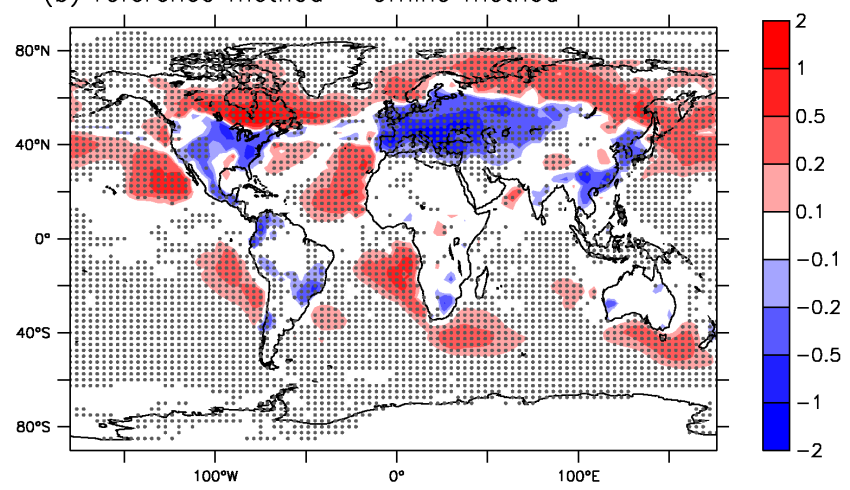

Fig. 11. (a) Reference method $\left(\mathrm{M}_{\mathrm{REF}}\right)$ radiative forcing of the first indirect effect $\left(\mathrm{W} \mathrm{m}^{-2}\right)$; (b) difference of radiative forcing between the reference method $\left(\mathrm{M}_{\mathrm{REF}}\right)$ and the off-line method $\left(\mathrm{CM}_{\mathrm{Offline}}\right)$. The statistical signifiance of the difference was tested at the $95 \%$ confidence level using a bootstrap method. Regions where the difference is statistically significant are indicated with dots.

present-day and preindustrial sulfate emissions. The preindustrial simulation is performed off-line with respect to the meteorological trajectory that is based on the present-day, fully-variable aerosol retroaction.

The instantaneous radiative forcing $\left(\mathrm{RF}_{\mathrm{V}}\right)$ is directly the difference between the net flux at the top of the atmosphere with present-day emissions $\left(F_{\mathrm{V} \_\mathrm{PD}}\right)$ and with preindustrial emissions $\left(F_{\mathrm{V}_{-} P I}\right)$ :

$\mathrm{RF}_{\mathrm{V}}=F_{\mathrm{V}_{-} \mathrm{PD}}-F_{\mathrm{V} \_\mathrm{PI}}$

The first indirect radiative forcing computed using this method is $-0.36 \mathrm{~W} \mathrm{~m}^{-2}$, a little less than using the off-line method $\left(-0.39 \mathrm{~W} \mathrm{~m}^{-2}\right)$ where averaged sulfate concentration fields are used. The first indirect effect (Fig. 11a) shows a very similar spatial distribution than the one obtained with the off-line method (Fig. 4b). The first indirect effect is more negative over Europe, the United-States and East Asia, and less negative over the boreal forests and in the eastern part of the ocean basins (Fig. 11b). The difference (estimated with a non-parametric bootstrap test) is statistically significant at

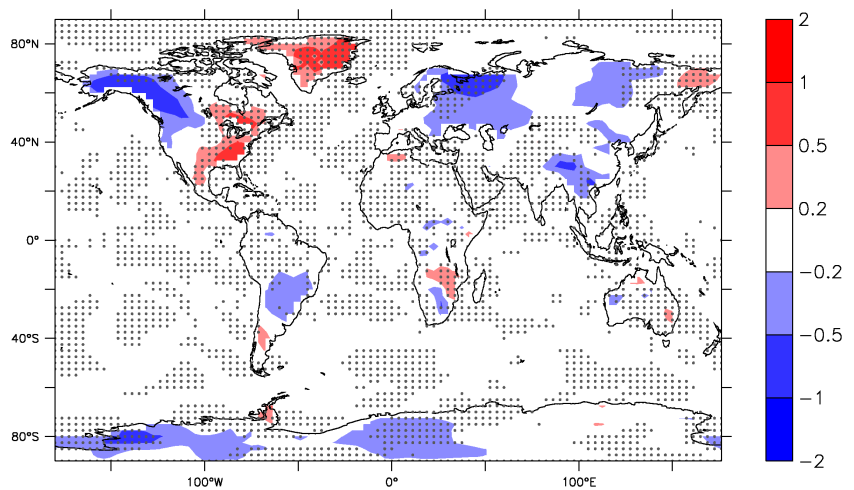

Fig. 12. Impact on surface temperature of coupling chemistry and climate: difference of temperature anomaly $\left(\Delta T=T_{\mathrm{PD}}-T_{\mathrm{PI}}\right)$ between on-line $\left(\Delta T_{\mathrm{V}}\right)$ and off-line configuration $\left(\Delta T_{\mathrm{M}}\right)$. The statistical signifiance of the difference was tested at the $95 \%$ confidence level using a student test. Regions where the difference is statistically significant are indicated with dots.

the $95 \%$ confidence level in most regions. These changes are only due to the frequency at which aerosols vary (monthly in the off-line case and $30 \mathrm{~min}$ in the reference case). The difference of meteorological trajectory between the reference method and the off-line one does not affect the result (not shown).

Given that the largest differences of radiative forcing between the two methods are over continents (Europe and North America), one could expect that although the SSTs are fixed, these differences of radiative forcing will have an impact on surface temperature over these regions. To distinguish the real effect of temporal variability on temperature from the noise due to natural variability of climate, $50-\mathrm{yr}$ simulations have been performed with off-line and on-line model configurations and for present-day and preindustrial periods. The difference of temperature over continents between the two periods has been estimated for both configurations of the models $\left(\Delta T_{\mathrm{V}}=T_{\mathrm{V}_{\text {_PD }}}-T_{\mathrm{V} \_ \text {PI }}\right.$ and $\Delta T_{\mathrm{M}}=$ $\left.T_{\mathrm{M} \text { PD }}-T_{\mathrm{M} \text { PI }}\right)$ and then compared. Globally, the difference $\left(\Delta T_{\mathrm{V}}-\Delta T_{\mathrm{M}}\right)$ amounts to $-0.07^{\circ} \mathrm{C}$. Regionally, the signal is within the interval $[-0.9,0.8]^{\circ} \mathrm{C}$ and is not well correlated with radiative forcing (Fig. 12). We conclude from this test that the temporal variability of aerosol does not affect surface temperature fields.

With this method, we get a reference estimate of the first indirect radiative forcing including sulfate temporal variability. However, the multiple calls needed that use a lot of CPU make it impractical to use for routine simulations. Thus, we now propose two alternatives to compute aerosol radiative forcing in on-line simulations. They rely on the results of Sect. 4.1 that showed that the same meteorological fields are needed to compute both present-day and preindustrial concentrations. 
Table 4. Monthly mean (M), standard deviation of daily values (STD) and ratio (M/STD) of the factor $F_{\mathrm{V} \_ \text {PI }}-F_{\mathrm{M} \text { PI }}$ used to correct the radiative forcing of the "extended off-line method".

\begin{tabular}{lllllllllllll}
\hline & JAN & FEB & MAR & APR & MAY & JUN & JUL & AUG & SEP & OCT & NOV & DEC \\
\hline M & 0.274 & 0.232 & 0.189 & 0.186 & 0.221 & 0.226 & 0.260 & 0.237 & 0.241 & 0.220 & 0.228 & 0.251 \\
STD & 0.038 & 0.061 & 0.028 & 0.032 & 0.030 & 0.041 & 0.035 & 0.031 & 0.041 & 0.060 & 0.087 & 0.041 \\
M/STD & 0.13 & 0.26 & 0.15 & 0.17 & 0.13 & 0.15 & 0.13 & 0.13 & 0.17 & 0.27 & 0.38 & 0.16 \\
\hline
\end{tabular}

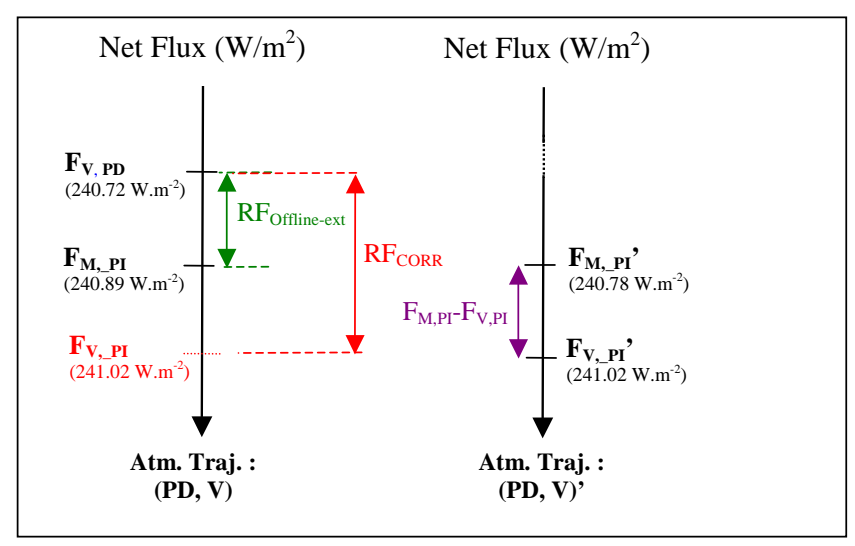

$\left.\begin{array}{l}\mathrm{RF}_{\mathrm{M}-\text { Offline-ext }}=-0.17 \mathrm{~W} \cdot \mathrm{m}^{-2} \\ \mathrm{~F}_{\mathrm{M}, \mathrm{PI}}-\mathrm{F}_{\mathrm{V}, \mathrm{PI}}=-0.23 \mathrm{~W} \cdot \mathrm{m}^{-2}\end{array}\right\} \mathrm{RF}_{\mathrm{CORR}}=-0.40 \mathrm{~W} \cdot \mathrm{m}^{-2}$

Fig. 13. Schematical representation of the error in the radiative forcing estimation computed from 2 sulfate fields which do not satisfy the criteria of having consistent meteorological fields. Correction with the " $F_{\mathrm{M}, \mathrm{PI}}-F_{\mathrm{V}, \mathrm{PI}}$ " term estimated in the Sect. 5.5. The fluxes do not include the impact of direct effect. Only the change due to the first indirect effect is taken into account.

In the first alternative method (Sect. 4.3), we propose to correct the error introduced on net fluxes by the use of "inconsistent" aerosol fields (one constant during the whole month; one varying at each time step). The correction is based on the difference between net fluxes calculated using pre-calculated monthly preindustrial concentrations and using $30 \mathrm{~min}$ preindustrial concentrations. Both preindustrial simulations are performed with the same meteorological trajectory. In the second alternative case (Sect. 4.4), we propose to estimate preindustrial sulfate concentration from presentday values. This ensures that both present and preindustrial sulfate concentrations are consistent with the meteorological trajectory of the simulation.

\subsection{Correction of off-line/on-line biaisis}

Computing preindustrial and present-day aerosol concentrations with two different meteorological trajectory results in an underestimation of $60 \%$ of the first indirect radiative forcing (see Sect. 4.1). This "off-line/on-line" error corresponds to the term " $F_{\mathrm{M}, \mathrm{PI}}-F_{\mathrm{V}, \mathrm{PI}}$ " (Fig. 13). This difference of net

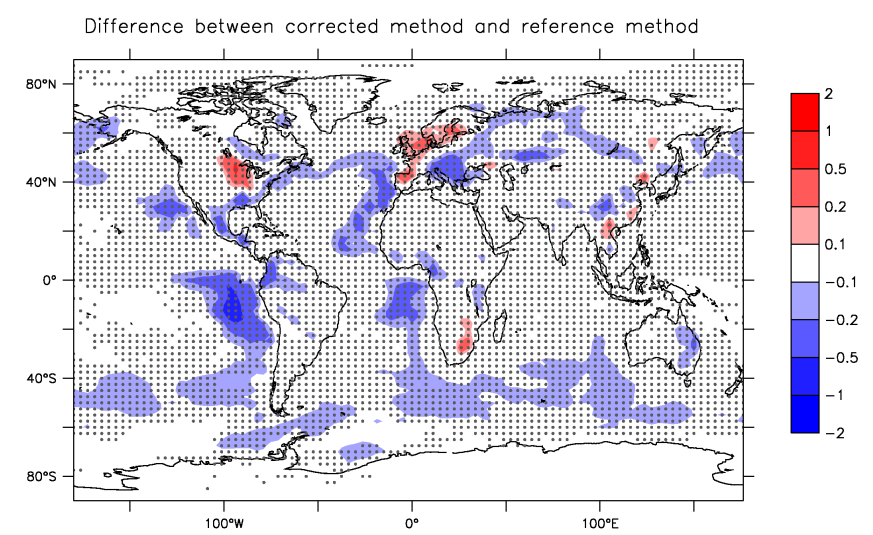

Fig. 14. Difference of the radiative forcing of the 1st indirect effect calculated from the extended off-line method corrected with the $\Delta \mathrm{NF}_{\mathrm{PI}}$ term and that one calculated in the reference method (experiment VAR) in $\mathrm{W} \mathrm{m}^{-2}$. The statistical signifiance of the difference was tested at the $95 \%$ confidence level using a bootstrap method. Regions where the difference is statistically significant are indicated with dots. Color bar of the first map varies from -10 and $+10 \mathrm{~W} \mathrm{~m}^{-2}$, whereas values of the second map (difference) vary from -2 and $+2 \mathrm{~W} \mathrm{~m}^{-2}$.

fluxes is due to the use of monthly vs. varying aerosol concentrations. It amounts to $-0.23 \mathrm{~W} \mathrm{~m}^{-2}$. Its geographical distribution is displayed in Fig. 6 b.

This error has a low day to day variability (Table 4). Then, we propose to assess monthly mean values of the error and use them to correct the monthly mean radiative forcings computed with the extended off-line simulation. Finally, the correction consists in summing up the term " $F_{\mathrm{M}, \mathrm{PI}}-F_{\mathrm{V}, \mathrm{PI}}$ " and the biased radiative forcing $\mathrm{RF}_{\text {offline_ext }}$ (Fig. 13):

$\mathrm{RF}_{\text {offline_ext_corr }}=\mathrm{RF}_{\text {offline_ext }}+F_{\mathrm{M}, \mathrm{PI}}-F_{\mathrm{V}, \mathrm{PI}}$

The direct radiative forcing remains unchanged compared to the estimation of the extended method off-line as any correction are applied for this effect. For the first indirect effect, the corrected radiative forcing amounts to $-0.41 \mathrm{~W} \mathrm{~m}^{-2}$. It is $13 \%$ less than the value calculated in our reference simulation. The difference of radiative forcing calculated with this method and with the reference method is presented in Fig. 14. A slight overestimation of the first indirect effect (more negative) concerns a major part of the globe: only a few grid points in the North of Europe, the East of the United States, and in South Africa present an underestimation. This 

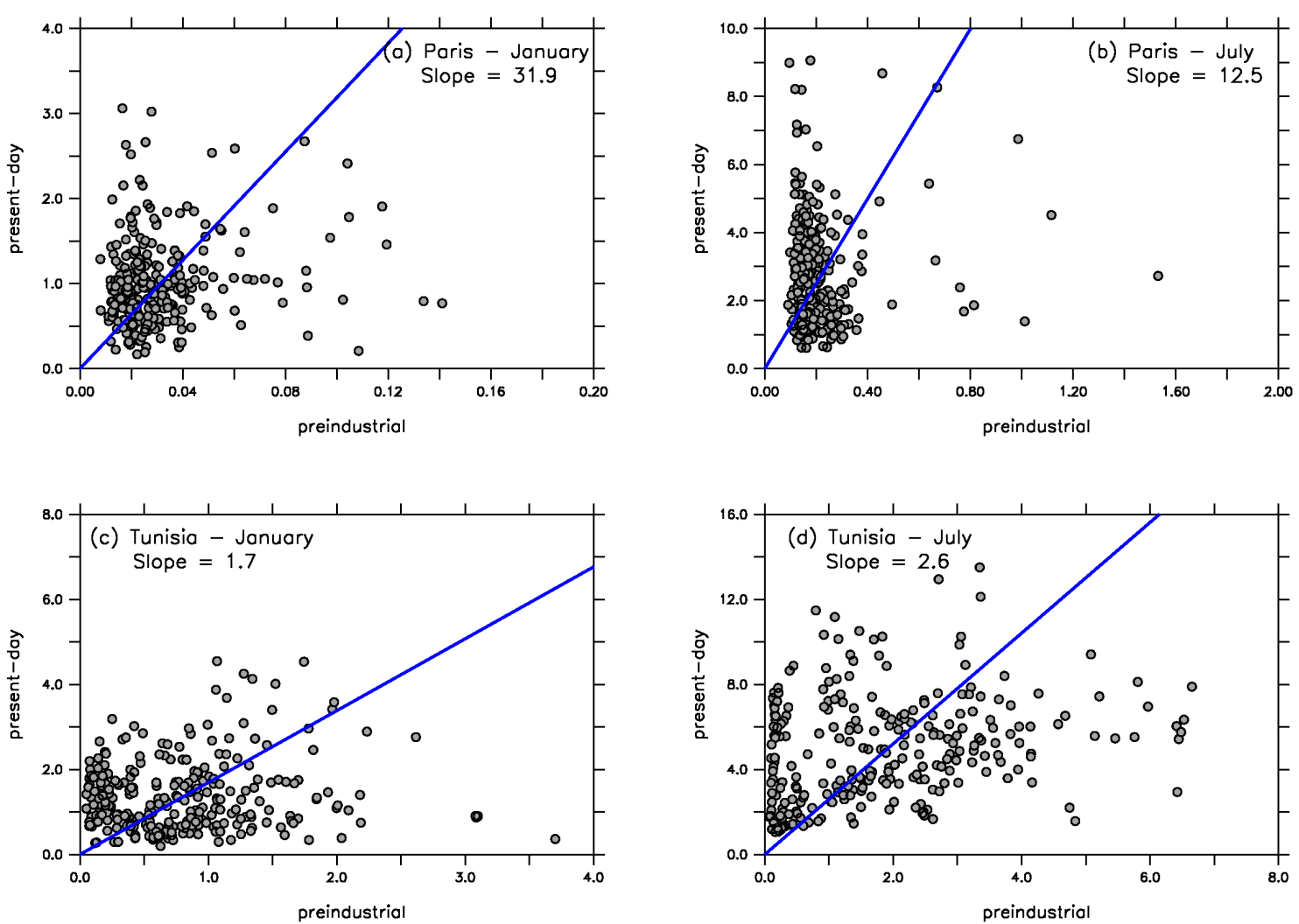

Fig. 15. Correlation between the present-day sulfate concentration and the preindustrial one for 2 grid points (Paris and Tunisia) and 2 months (January and July). The blue line represents the expected values of the actual by the preindustrial instantaneous ratio, considering it is the same as the ratio of monthly mean concentrations. Slopes indicate the values of the monthly mean ratio.

overestimation is statistically significant at the $95 \%$ confidence level (bootstrap test).

Compared to the reference method (Sect. 4.1), the global error $\left(-0.05 \mathrm{~W} \mathrm{~m}^{-2}, 13 \%\right)$ is slightly higher that the one computed from monthly averaged concentration fields $\left(-0.03 \mathrm{~W} \mathrm{~m}^{-2}, 8 \%\right)$ with the off-line methods and MONTH experiment. However, these values are low, and this method largely improves regional patterns (Fig. 14 versus Fig. 11b).

The residual error is mainly due to a residual difference of meteorological trajectories: the inconsistence related to the calculation of sulfate concentration has been corrected, but the terms $\mathrm{RF}_{\text {online_ext }}$ and " $F_{\mathrm{M}, \mathrm{PI}}-F_{\mathrm{V}, \mathrm{PI}}$ " have been estimated from two different meteorological trajectories (see Fig. 13). Secondly, the hypothesis for this case is not perfectly matched as the " $F_{\mathrm{M}, \mathrm{PI}}-F_{\mathrm{V}, \mathrm{PI}}$ " term presents a small variability.

Finally, this method is valid for aerosol studies but not for more complex cases in which several forcings are simultaneously modified (climate simulation).

\subsection{Approximation of the on-line aerosol preindustrial concentration}

For this method, we expect that at a given time, for a similar meteorology, the ratio of preindustrial by actual instantaneous concentrations is the same that the ratio of monthly mean concentrations:

At a given time $t$ of a given month:

$\frac{\left[\mathrm{SO}_{4}\right]_{\mathrm{pi,t}}}{\left[\mathrm{SO}_{4}\right]_{\mathrm{pr}, \mathrm{t}}}=\frac{\left[\mathrm{SO}_{4}\right]_{\mathrm{p}, \text { month }}}{\left[\mathrm{SO}_{4}\right]_{\mathrm{pr}, \text { month }}}=$ preindustrial aerosol fraction

Figure 15 shows that the variability of the instantaneous sulfate concentration ratio is not completely caught by this approach. However, one can get a rough estimate using this hypothesis.

In this method, the on-line configuration of the model is used. The preindustrial concentration field is calculated in multiplying the present-day aerosol concentration field (computed interactively in INCA) by the "preindustrial aerosol fraction". The fraction is prescribed monthly. It is obtained from preindustrial and present sulfate fields that have been computed in previous simulations using the chemicaltransport version of LMDZ-INCA. 
(a) Direct effect

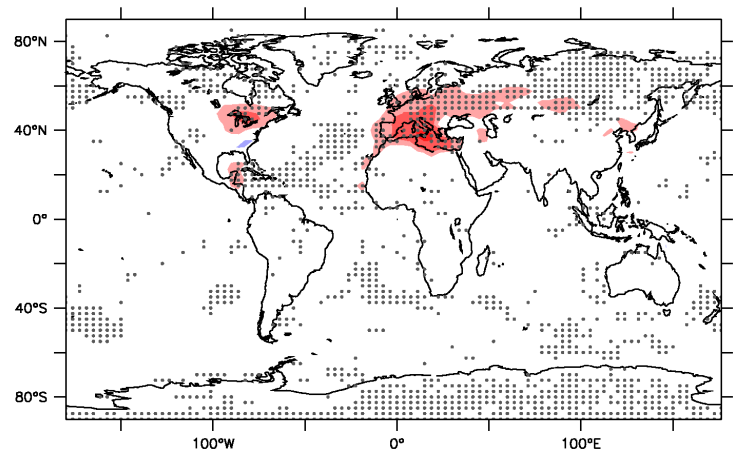

(b) First indirect effect

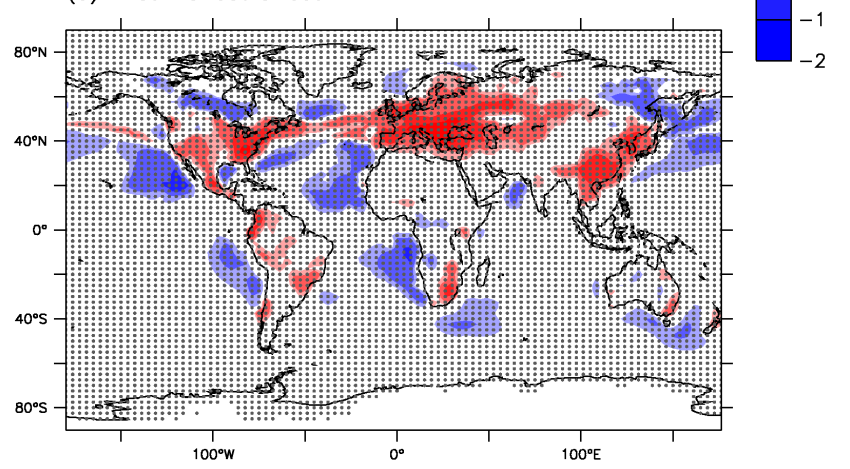

Fig. 16. (a) Difference of radiative forcing between the method using an approximation of the on-line preindustrial concentration and the extended off-line method for the direct effect (in $\mathrm{W} \mathrm{m}^{-2}$ ); (b) difference of radiative forcing between the method using an approximation of the on-line preindustrial concentration and the reference method for the first indirect effect (in $\mathrm{W} \mathrm{m}^{-2}$ ). The statistical signifiance of the difference was tested at the $95 \%$ confidence level using a bootstrap method. Regions where the difference is statistically significant are indicated with dots.

The direct radiative forcing amounts to $-0.31 \mathrm{~W} \mathrm{~m}^{-2}$. It is very close to the values obtained with the off-line method (Sect. 3.2) and the extended off-line method (Sect. 4.1). The geographical distribution of the direct effect displays the same patterns that those obtained in the two other methods (see Fig. 16a for the difference with the extended off-line method). Only the regions of high sulfate concentrations are impacted.

The first indirect effect amounts to $-0.36 \mathrm{~W} \mathrm{~m}^{-2}$ that matches up to the value of the reference method $\left(-0.36 \mathrm{~W} \mathrm{~m}^{-2}\right)$. Figure $16 \mathrm{~b}$ shows the remaining differences in the geographical distribution. As for the other tested methods, this difference is statistically significant (bootstrap test at the $95 \%$ confidence level) in most regions. The difference of patterns obtained between this method and the reference method is close to the one obtained between the offline method and the reference method (Fig. 11b). Using this

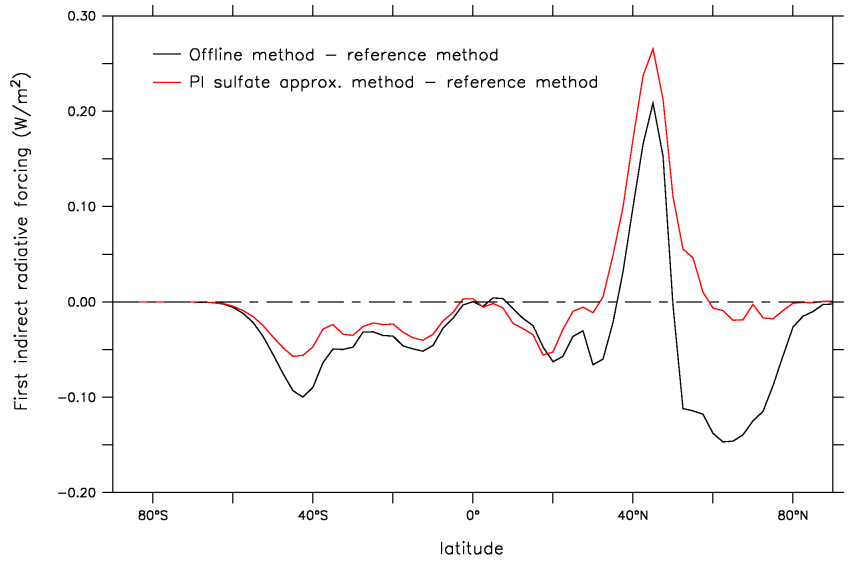

Fig. 17. Zonal mean of the difference of first indirect radiative forcing $\left(\mathrm{W} \mathrm{m}^{-2}\right)$ of the off-line method (black) and the preindustrial sulfate concentration approximation method (red) compared to the reference method.

last method improves spatial patterns (Fig. 17), especially in regions of northern high latitude.

The remaining error in the estimate of the first indirect effect radiative forcing is caused by how we approximate the preindustrial aerosol concentration fields.

\subsection{Comparison of the results}

All tested methods give very similar estimates of the direct radiative forcing but significative differences for the first indirect effect. Figure 18 compares the performance of the tested methods to compute the first indirect radiative forcing (mean bias and error on the spatial pattern). Estimates of the root mean squared error and feasibility of each method are also summarised in Table 5.

Even though the method based on the approximation of the preindustrial sulfate concentration leads to the best result regarding the mean bias, the extended off-line method with correction represents best the spatial pattern of the first indirect effect (comparison to the reference method). This method presents also the lowest root mean squared error. Regarding the technical feasibility and ability to perform climate studies, the method based on the approximation of the preindustrial sulfate concentration is by far the best method since it is simple to implement, relatively cheap computationally (even though preliminar chemistry-transport simulations are needed to compute the monthly mean aerosol fraction), and enables us to analyze several perturbations simultaneously.

This last method has been implemented in the Earth System Model of the Institut Pierre Simon Laplace (IPSL) and will be used for climate simulations including aerosols studies. 

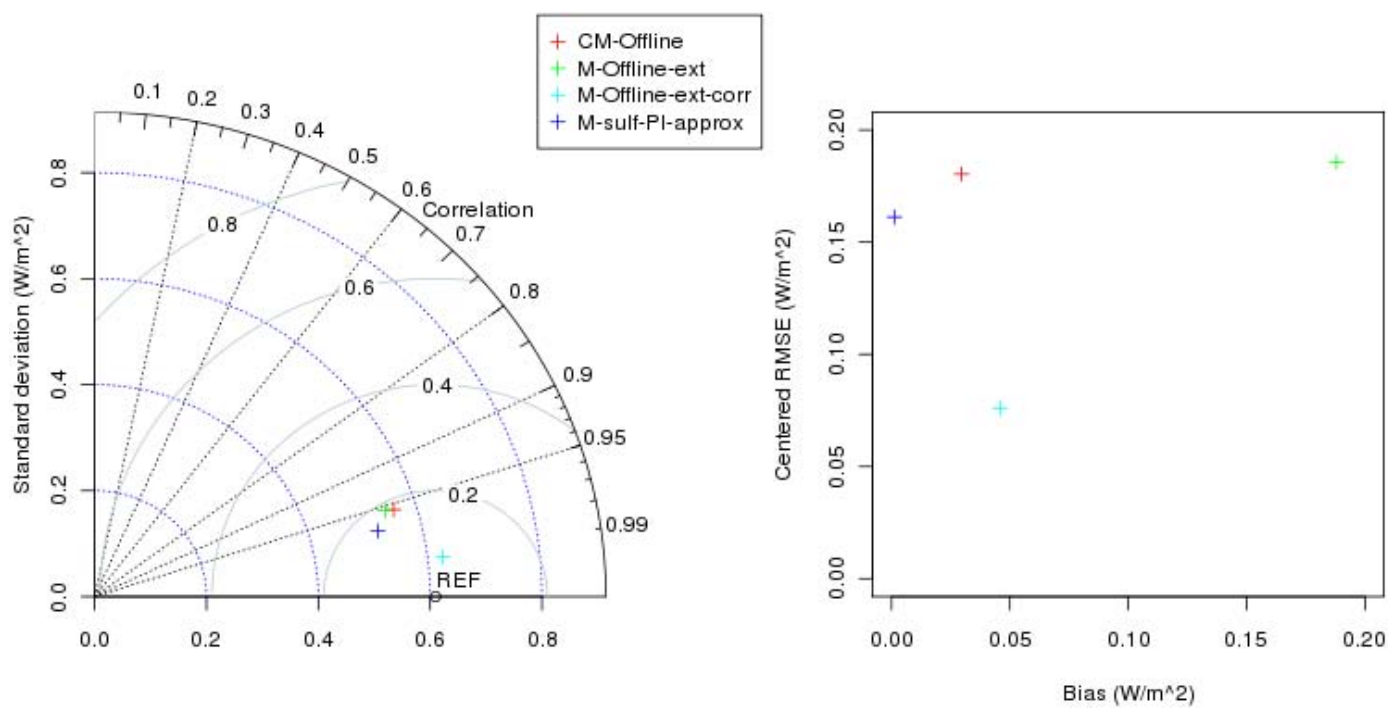

Fig. 18. Comparison of biases on the estimation of the first indirect radiative forcing computed with the four tested methods and relative to the reference method: off-line method (red), extended off-line method (green); corrected extended off-line method (cyan) preindustrial sulfate concentration approximation method (blue). Taylor diagram (left) presents the performance of methods to represent the spatial pattern of the first indirect effect (including standard deviation, correlation and centered root mean squared error). Right: scatter plot compares the mean bias and the standard deviation of the error for each method.

Table 5. Estimation of the error on the root mean squared error (RMSE) of the first indirect radiative forcing for the different methods presented in this paper. The REF method is used as reference. "No RF" indicates that the method does not enable radiative forcing assessment. The second row "feasibility" is related to the technical feasibility of the method.

\begin{tabular}{lcccccc}
\hline & $\mathrm{M}_{\text {REF }}$ & $\mathrm{CM}_{\text {Offline }}$ & $\mathrm{CM}_{- \text {Online }}$ & $\mathrm{M}_{\text {Offline_ext }}$ & $\mathrm{M}_{\text {Offline_ext-corr }}$ & M $_{\text {Sulf-PI-approx }}$ \\
\hline RMSE & 0 & 0.18 & No RF & 0.27 & 0.09 & 0.16 \\
feasibility & no & yes & yes & yes & yes & yes \\
\hline
\end{tabular}

\section{Conclusions}

The impact of coupling a climate model to a chemistry/aerosol model has been addressed using the LMDz general circulation model and the chemistry-aerosol module INCA. This coupling is in agreement with the actual trend of a more integrated Earth System Model for studying climate. With this model configuration, simulations include a complete feedback between climate and aerosols. The cloud/aerosol interaction is computed in LMDZ using an empirical parameterization and considers sulfate as the only aerosol type in this study. The conclusion would be similar for a more complex representation of aerosol. Absorbing aerosols would introduce additional non-linearities through the semi direct effect (modification of the meteorological conditions of the atmosphere). However, they have no effects on the $\mathrm{CDNC/Na}$ relationship that is the main source of non-linearities for this study. This conclusion could differ for models using a mechanistic activation scheme.

We restricted this study to the direct and first indirect effects. The impact of this coupling on the 2 nd indirect effect is beyond the scope of the paper.
Temporal variability results in an increase of net fluxes that is mainly due to the non-linearity of the first indirect effect. The temporal variability has a negligible role on the direct effect. The changes are mainly controlled by two factors: lowlevel clouds and the magnitude of the aerosol mass concentrations. The larger the amount of low-level clouds, the larger is the effect on radiative fluxes. The uncertainties associated to the parameterisation of low-level clouds in LMDz (Rio, 2007) have likely repercussions on our estimates of net flux changes.

The level of sulfate concentration has two opposite effects: (1) the non-linearity of the first indirect effect diminishes as the sulfate concentrations increase; (2) the sulfate temporal variability increases with increasing sulfate concentrations. The detailed analysis of several regions around the globe results in the differentiation of three ranges of concentration. Regions of low sulfate concentration (less than $\left.0.1 \mu \mathrm{g}\left(\mathrm{SO}_{4}\right) \mathrm{m}^{-3}\right)$, for which the non-linearity effect of the relationship is dominant but the sulfate variability is very low. Regions of intermediate concentrations (between 0.1 and $\left.0.8 \mu \mathrm{g}\left(\mathrm{SO}_{4}\right) \mathrm{m}^{-3}\right)$ for which the effect of temporal variability is maximum. Regions of high sulfate concentrations 
(above $0.8 \mu \mathrm{g}\left(\mathrm{SO}_{4}\right) \mathrm{m}^{-3}$ ) for which the relationship $N_{\mathrm{d}}-m_{\mathrm{s}}$ is almost linear and the effect on the radiative fluxes is negligible. The threshold concentrations indicated here are only indicative as they would vary depending on the formulation of the first indirect effect and on the GCM used.

Computing sulfate direct radiative forcing with the online configuration of the model is quite easy. Global mean $\left(-0.32 \mathrm{~W} \mathrm{~m}^{-2}\right)$ and regional patterns are very close to those obtained with the off-line configuration $\left(-0.31 \mathrm{~W} \mathrm{~m}^{-2}\right)$.

On the other hand, coupling climate and aerosols in a model makes it difficult to compute the forcing from the first indirect radiative effect. Technical solutions have been proposed to tackle this difficulty. First, a reference method has been developed to compute the first indirect radiative forcing with the on-line configuration. Though globally, the radiative forcing is very close to the one computed with the off-line configuration; the climate/aerosols coupling greatly influences the regional patterns. However, this method is not suited to run long climate simulations because of its difficult implementation and high CPU cost (chemistry module should be run 3 times to get radiative forcing).

Then, alternatives to the reference method have been elaborated to compute radiative forcing in on-line configuration. The alternative methods will need further development to be used with a prognostic cloud number concentration. Making a direct extension of the off-line classical configuration (the present-day concentration is calculated on-line as the preindustrial one is prescribed) results in an error of more than $60 \%$ on the first indirect radiative forcing. We show that it is mainly due to the non-linearity of this effect. This method must be avoided.

Two other alternatives give satisfactory results. The first one consists in making a correction of the bias as described above. This could be achieved via two additional simulations for unperturbed conditions (the first one with the off-line configuration and the second one with the on-line configuration). With this correction, the global mean estimate of the first indirect radiative forcing is overestimated but spatial patterns are improved compared to the results with the offline method.

In the second alternative, the preindustrial sulfate concentration is approximated using the ratio of unperturbed to perturbed sulfate concentration. In spite of an underestimation of the variability of this ratio, this method gives very good global results and improves regional patterns compared to the off-line configuration.

Both of these alternatives would imply running additional simulations (including chemistry module) that would increase significantly the total CPU time. Thus the "lower CPU" method remains still to run additional simulations with the off-line configuration of the model for time-slices of interest.
Acknowledgements. This work was financed as part of the doctoral Thesis of Celine Deandreis by the "Comissariat à l'Energie Atomique" (CEA). Computer time was provided by the CCRT/GENCI computer center of the CEA. We would like to thank Johannes Quaas and two anonymous referees for their useful comments on previous versions of this paper.

Edited by: J. Quaas

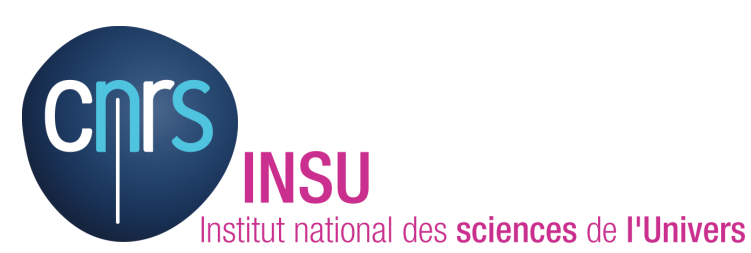

The publication of this article is financed by CNRS-INSU.

\section{References}

Abdul-Razzak, H. and Ghan, S. J.: A parameterization of aerosol activation: 3. Sectional representation, J. Geophys. Res., 107, 4026, doi:10.1029/2001JD000483, 2002.

Boer, G. J., Flato, G. M., and Ramsden, D.: A transient climate change simulation with greenhouse gas and aerosol forcing: projected climate to the 21 st century, Clim. Dynam., 16, 427-450, 2000.

Bony, S., and Emmanuel, K. A.: A parameterization of the cloudiness associated with cumulus convection; evaluation using TOGA COARE data, J. Atmos. Sci., 58, 3158-3183, 2001.

Boucher, O. and Lohmann, U.: The sulfate-CCN-cloud albedo effect: A sensitivity study with two general circulation models, Tellus B, 47, 281-300, 1995.

Boucher, O., Pham, M., and Venkataraman, C.: Simulation of the atmospheric sulfur cycle in the Laboratoire de Meteorologie Dynamique General Circulation Model. Model description, model evaluation, and global and European budgets, Note Technique de l'IPSL no 23, 2002.

Chen, Y. and Penner, J. E.: Uncertainty analysis for estimates of the first indirect aerosol effect, Atmos. Chem. Phys., 5, 2935-2948, doi:10.5194/acp-5-2935-2005, 2005.

Chuang, C. C., Penner, J. E., Taylor, K. E., Grossman, A. S., and Walton, J. J.: An assessment of the radiative effects of anthropogenic sulfate, J. Geophys. Res., 102, 3761-3778, 1997.

Dai, A., Wigley, T. M. L., Boville, B. A., Kiehl, J. T., and Buja, L. E.: Climates of the 20th and 21 st centuries simulated by the NCAR climate system model, J. Climate, 14, 485-519, 2001.

Dentener, F., Kinne, S., Bond, T., Boucher, O., Cofala, J., Generoso, S., Ginoux, P., Gong, S., Hoelzemann, J. J., Ito, A., Marelli, L., Penner, J. E., Putaud, J.-P., Textor, C., Schulz, M., van der Werf, G. R., and Wilson, J.: Emissions of primary aerosol and precursor gases in the years 2000 and 1750 prescribed data-sets for AeroCom, Atmos. Chem. Phys., 6, 4321-4344, doi:10.5194/acp-64321-2006, 2006.

Dufresne, J.-L., Quaas, J., Boucher, O., Denvil, S., and Fairhead, L.: Contrasts in the effects on climate of anthropogenic sulfate aerosols between the 20th and the 21 st century, Geophys. Res. Lett., 32, L21703, doi:10.1029/2005GL023619, 2005. 
Emmanuel, K.: A scheme for representing cumulus convection in large-scale models, J. Atmos. Sci., 48, 2313-2335, 1991.

Forster, P., Ramaswamy, V., Artaxo, P., Berntsen, T., Betts, R., Fahey, D.W., Haywood, J., Lean, J., Lowe, D. C., Myhre, G., Nganga, J., Prinn, R., Raga, G., Schulz, M., and Van Dorland, R.: Changes in Atmospheric Constituents and in Radiative Forcing, in: Climate Change 2007: The Physical Science Basis. Contribution of Working Group I to the Fourth Assessment Report of the Intergovernmental Panel on Climate Change, edited by: Solomon, S., Qin, D., Manning, M., Chen, Z., Marquis, M., Averyt, K. B., Tignor, M., and Miller, H. L., Cambridge University Press, Cambridge, United Kingdom and New York, NY, USA, 2007.

Fouquart, Y. and Bonnel, B.: Computations of solar heating of the Earth's atmosphere: A new parameterization, Contrib. Atmos. Phys., 53, 35-62, 1980.

Gerber, H. E.: Relative-humidity parameterization of the navy aerosol model (NAM), Naval Research Laboratory, Washington, Report No. NRL Report 8956, 17 pp., 1985.

Guelle, W., Balkanski, Y. J., Dibb, J. E., Schulz, M., and Dulac, F.: Wet deposition in a global size-dependent aerosol transport model 2. Influence of the scavenging scheme on ${ }^{210} \mathrm{~Pb}$ vertical profiles, surface concentrations, and deposition, J. Geophys. Res., 103, 28875-28892, 1998a.

Guelle, W., Balkanski, Y. J., Schulz, M., Dulac, F., and Monfray, P.: Wet deposition in a global size-dependent aerosol transport model 1. Comparison of a 1 year ${ }^{210} \mathrm{~Pb}$ simulation with ground measurements, J. Geophys. Res., 103, 11429-11446, 1998 b.

Hansen, J., Sato, M., Ruedy, R., Lacis, A., Asamoah, K., Beckford, K., Borenstein, S., Brown, E., Cairns, B., Carlson, B., Curran, B., de Castro, S., Druyan, L., Etwarrow, P., Ferede, T., Fox, M., Gaffen, D., Glascoe, J., Gordon, H., Hollandsworth, S., Jiang, X., Johnson, C., Lawrence, N., Lean, J., Lerner, J., Lo, K., Logan, J., Luckett, A., McCormick, M. P., McPeters, R., Miller, R., Minnis, P., Ramberran, I., Russell, G., Russell, P., Stone, P., Tegen, I., Thomas, S., Thomason, L., Thompson, A., Wilder, J., Willson, R., and Zawodny, J.: Forcings and chaos in interannual to decadal climate change, J. Geophys. Res., 102, 25679-25720, 1997.

Hansen, J., Sato, M., Nazarenko, L., Ruedy, R., Lacis, A., Koch, D., Tegen, I., Hall, T., Shindell, D., Santer, B., Stone, P., Novakov, T., Thomason, L., Wang, R., Wang, Y., Jacob, D., Hollandsworth, S., Bishop, L., Logan, J., Thompson, A., Stolarski, R., Lean, J., Willson, R., Levitus, S., Antonov, J., Rayner, N., Parker, D., and Christy, J.: Climate forcings in Goddard Institute for Space Studies SI2000 simulations, J. Geophys. Res., 107, 4347, doi:10.1029/2001JD001143, 2002.

Hauglustaine, D. A., Hourdin, F., Jourdain, L., Filiberti, M. A., Walters, S., Lamarque, J.-F., and Holland, E. A.: Interactive chemistry in the Laboratoire de Météorologie Dynamique general circulation model: Description and background tropospheric chemistry evaluation, J. Geophys. Res., 109, D04314, doi:10.1029/2003JD003957, 2004.

Haywood, J. M., Stouffer, R. J., Wetherald, R. T., Manabe, S., and Ramaswamy, V.: Transient response of a coupled model, to estimated changes in greenhouse gas and sulfate concentrations, Geophys. Res. Lett., 24, 1335-1338, 1997.

Hourdin, F., Musat, I., Bony, S., Braconnot, P., Codron, F., Dufresne, J.-L., Fairhead, L., Filiberti, M.-A., Friedlingstein, P., Grandpeix, J.-Y., Krinner, G., Levan, P., Li, Z.-X., and Lott, F.:
The LMDZ4 general circulation model: climate performance and sensitivity to parametrized physics with emphasis on tropical convection, Clim. Dynam., 27, 787-813, 2006.

IPCC: Climate Change 2001: The Scientific Basis. Contribution of Working Group I to the Third Assessment Report of the Intergovernmental Panel on Climate Change, edited by: Houghton, J. T., Ding, Y., Griggs, D. J., Noguer, M., van der Linden, P. J., Dai, X., Maskell, K., and Johnson, C. A., Cambridge University Press, Cambridge, UK and New York, NY, USA, 881 pp., 2001.

Jones, A., Roberts, D. L., and Slingo, A.: A climate model study of the indirect radiative forcing by anthropogenic aerosols, Nature, 370, 450-453, 1994.

Jones, A., Roberts, D. L., Woodage, M. J., and Johnson, C. E.: Indirect sulfate aerosol forcing in a climate model with an interactive sulphur cycle, J. Geophys. Res., 106, 20293-20310, 2001.

Lohmann, U. and Feichter, J.: Impact of sulfate aerosols on albedo and lifetime of clouds: A sensitivity study with the ECHAM GCM, J. Geophys. Res., 102, 13685-13700, 1997.

Lohmann, U., Rotstayn, L., Storelvmo, T., Jones, A., Menon, S., Quaas, J., Ekman, A. M. L., Koch, D., and Ruedy, R.: Total aerosol effect: radiative forcing or radiative flux perturbation?, Atmos. Chem. Phys., 10, 3235-3246, doi:10.5194/acp-10-32352010, 2010.

Lott, F.: Alleviation of stationary biases in a GCM through a mountain drag parametrization scheme and a simple representation of mountain lift forces, Mon. Weather Rev., 127, 788-801, 1999.

Martin, S. T., Hung, H.-M., Park, R. J., Jacob, D. J., Spurr, R. J. D., Chance, K. V., and Chin, M.: Effects of the physical state of tropospheric ammonium-sulfate-nitrate particles on global aerosol direct radiative forcing, Atmos. Chem. Phys., 4, 183214, doi:10.5194/acp-4-183-2004, 2004.

Menon, S., DelGenio, A. D., Koch, D., and Tselioudis, G.: GCM Simulations of the Aerosol Indirect Effect: Sensitivity to Cloud Parameterization and Aerosol Burden, J. Atmos. Sci., 59, 692713, 2002.

Mitchell, J. F. B. and Johns, T. C.: On modification of global warming by sulfate aerosols, J. Climate, 10, 245-267, 1997.

Morcrette, J.-J.: Evaluation of model-generated cloudiness: Satelliteobserved and model-generated diurnal variability of brightness temperature, Mon. Weather Rev., 119, 1205-1224, 1991.

Nenes, A. and Seinfeld, J. H.: Parameterization of cloud droplet formation in global climate models, J. Geophys. Res., 108, 4415, doi:10.1029/2002JD002911, 2003.

Penner, J. E., Quaas, J., Storelvmo, T., Takemura, T., Boucher, O., Guo, H., Kirkevåg, A., Kristjánsson, J. E., and Seland, Ø.: Model intercomparison of indirect aerosol effects, Atmos. Chem. Phys., 6, 3391-3405, doi:10.5194/acp-6-3391-2006, 2006.

Quaas, J. and Boucher, O.: Constraining the first aerosol indirect radiative forcing in the LMDZ GCM using POLDER and MODIS satellite data, Geophys. Res. Lett., 32, L17814, doi:10.1029/2005GL023850, 2005.

Quaas, J., Boucher, O., Dufresne, J.-L., and Le Treut, H. : Impacts of greenhouse gases and aerosol direct and indirect effects on clouds and radiation in atmospheric GCM simulations of the 1930-1989 period, Clim. Dynam., 23, 779-789, 2004.

Quaas, J., Ming, Y., Menon, S., Takemura, T., Wang, M., Penner, J. E., Gettelman, A., Lohmann, U., Bellouin, N., Boucher, O., Sayer, A. M., Thomas, G. E., McComiskey, A., Feingold, G., Hoose, C., Kristjánsson, J. E., Liu, X., Balkanski, Y., Donner, L. 
J., Ginoux, P. A., Stier, P., Grandey, B., Feichter, J., Sednev, I., Bauer, S. E., Koch, D., Grainger, R. G., Kirkevåg, A., Iversen, T., Seland, Ø., Easter, R., Ghan, S. J., Rasch, P. J., Morrison, H., Lamarque, J.-F., Iacono, M. J., Kinne, S., and Schulz, M.: Aerosol indirect effects - general circulation model intercomparison and evaluation with satellite data, Atmos. Chem. Phys., 9, 8697-8717, doi:10.5194/acp-9-8697-2009, 2009.

Reddy, M. S., Boucher, O., Balkanski, Y., and Schulz, M.: Aerosol optical depths and direct radiative perturbations by species and source type, Geophys. Res. Lett., 32, L12803, doi:10.1029/2004GL021743, 2005.

Rio, C.: Paramétrisation de la couche limite atmosphérique convective et représentation du cycle diurne des nuages dans un modèle de climat, Doctorat LMD, LMD, 2007.

Roelofs, G., Lelieveld, J., and Laurens, G.: Simulation of global sulfate distribution and the influence on effective cloud drop radii with a coupled photochemistry sulfur cycle model, Tellus B, 50, 224-242, 1998.

Roeckner, E., Stier, P., Feichter, J., Kloster, S., Esch, M., and Fischer-Bruns, I.: Impact of carbonaceous aerosol emissions on regional climate change, Clim. Dynam., 27, 553-571, 2006.

Rotstayn, L. D. and Penner, J. E.: Indirect aerosol forcing, quasiforcing, and climate response, J. Climate, 14, 2960-2975, 2001.

Schulz, M.: Constraining model estimates of the aerosol radiative forcing, Habilitation Thesis, Université Pierre et Marie Curie, Paris VI, 2007.

Schulz, M., Balkanski, Y., Dulac, F., and Guelle, W.: Role of aerosol size distribution and source location in a three-dimensional simulation of a Saharan dust episode tested against satellite-derived optical thickness, J. Geophys Res, 103, 10579-10592, 1998.
Schulz, M., Textor, C., Kinne, S., Balkanski, Y., Bauer, S., Berntsen, T., Berglen, T., Boucher, O., Dentener, F., Guibert, S., Isaksen, I. S. A., Iversen, T., Koch, D., Kirkevåg, A., Liu, X., Montanaro, V., Myhre, G., Penner, J. E., Pitari, G., Reddy, S., Seland, $\varnothing$., Stier, P., and Takemura, T.: Radiative forcing by aerosols as derived from the AeroCom present-day and pre-industrial simulations, Atmos. Chem. Phys., 6, 5225-5246, doi:10.5194/acp-65225-2006, 2006.

Shine K. P., Cook, J., Highwood, E. J., and Joshi, M.: An alternative to radiative forcing for estimating the relative importance of climate change mechanisms, Geophys. Res. Lett., 30, 2047, doi:10.1029/2003GL018141, 2003.

Stephens, S. E.: Radiation profiles in extended water clouds. II: Parameterization schemes, J. Atmos. Sci., 35, 2123-2132, 1978.

Suzuki, K., Nakajima, T., Numaguti, A., Takemura, T., Kawamoto, K., and Higurashi, A.: A study of the aerosol effect on a cloud field with simultaneous use of GCM modeling and satellite observation, J. Atmos. Sci., 61, 179-193, 2004.

Toon, O. B., Pollack, J. B., and Khare, B. N.: The optical constants of several atmospheric aerosol species: Ammonium sulfate, aluminium oxide and sodium chloride, J. Geophys. Res, 81, 57335748, 1976.

Twomey, S.: Pollution and the planetary albedo, Atmos. Environ., 8, 1251-1256, 1974. 